Review Article

\title{
Dysphagia, Speech, Voice, and Trismus following Radiotherapy and/or Chemotherapy in Patients with Head and Neck Carcinoma: Review of the Literature
}

\author{
B. J. Heijnen, ${ }^{1}$ R. Speyer, ${ }^{1,2}$ B. Kertscher, ${ }^{3}$ R. Cordier, ${ }^{2,4}$ K. W. J. Koetsenruijter, ${ }^{5}$ \\ K. Swan, ${ }^{6}$ and H. Bogaardt ${ }^{7}$ \\ ${ }^{1}$ Department of Otorhinolaryngology and Head and Neck Surgery, Leiden University Medical Centre, Leiden, Netherlands \\ ${ }^{2}$ College of Healthcare Sciences, James Cook University, Townsville, QLD, Australia \\ ${ }^{3}$ Kantonsspital Winterthur, Winterthur, Switzerland \\ ${ }^{4}$ School of Occupational Therapy and Social Work, Curtin University, Perth, WA, Australia \\ ${ }^{5}$ Department of Family Medicine, School of Health Professions Education (SHE), Maastricht University Medical Centre, \\ Maastricht, Netherlands \\ ${ }^{6}$ Speech Pathology Service, Gold Coast Health, Brisbane, QLD, Australia \\ ${ }^{7}$ Discipline of Speech Pathology, Faculty of Health Sciences, The University of Sydney, Sydney, NSW, Australia
}

Correspondence should be addressed to B. J. Heijnen; b.j.heijnen@lumc.nl

Received 27 May 2016; Accepted 1 August 2016

Academic Editor: Kenneth W. Altman

Copyright (C) 2016 B. J. Heijnen et al. This is an open access article distributed under the Creative Commons Attribution License, which permits unrestricted use, distribution, and reproduction in any medium, provided the original work is properly cited.

\begin{abstract}
Introduction. Patients with head and neck cancer suffer from various impairments due to the primary illness, as well as secondary consequences of the oncological treatment. This systematic review describes the effects of radiotherapy and/or chemotherapy on the functions of the upper aerodigestive tract in patients with head and neck cancer. Methods. A systematic literature search was performed by two independent reviewers using the electronic databases PubMed and Embase. All dates up to May 2016 were included. Results. Of the 947 abstracts, sixty articles met the inclusion criteria and described one or more aspects of the sequelae of radiotherapy and/or chemotherapy. Forty studies described swallowing-related problems, 24 described voice-related problems, seven described trismus, and 25 studies described general quality of life. Only 14 articles reported that speech pathologists conducted the interventions, of which only six articles described in detail what the interventions involved. Conclusion. In general, voice quality improved following intervention, whereas quality of life, dysphagia, and oral intake deteriorated during and after treatment. However, as a consequence of the diversity in treatment protocols and patient characteristics, the conclusions of most studies cannot be easily generalised. Further research on the effects of oncological interventions on the upper aerodigestive tract is needed.
\end{abstract}

\section{Introduction}

Head and neck oncological patients suffer from various functional, physical, and emotional impairments due to both the primary illness and the secondary consequences of the tumor treatment [1]. The oncological treatment of head and neck tumors depends on the location and the stage of the tumor, as well as the treatment preferences of the individual patient. Head and neck oncological treatment can include surgery, radiotherapy, chemotherapy, or combinations of these. The impact of head and neck oncological treatments on the anatomical structures, organ function, and the quality of life (QoL) should not be underestimated [2]. For instance, the implications of loss of function for people treated nonsurgically for head and neck cancer (HNC) and its detrimental effects on functioning and QoL are well documented [3].

In order to assist people with dysphagia to adjust to and live successfully with the sequelae of the primary condition, speech pathologists managing this caseload need to ensure posttreatment services are available [4] that address not only the physical but also the emotional and psychosocial needs. A qualitative study by Nund et al. [5] exploring dysphagia 
management by speech pathologists suggests that care givers generally feel ill-prepared for their role. Furthermore, this study suggests that clinicians should provide adequate and timely training and support to carers. Furthermore, Krisciunas et al. [6] concluded that within speech pathology there is no standardised therapy for HNC patients and scant evidence to support any particular protocol. As a result, institutions and individual speech pathologists need to develop their own protocols based on "standard" practices or anecdotal evidence.

Evidence-based practice (EBP) is hailed to be paramount in the practice of speech pathology [7]. The American Speech-Language-Hearing Association (ASHA) defines evidence-based practice as "... an approach in which current, high-quality research evidence is integrated with practitioner expertise and client preferences and values, into the process of making clinical decisions" [8]. Essentially, EBP involves moving the foundation for clinical decisions from clinical protocols centered solely on expert opinion to the integration of clinical expertise, the best current research evidence, and individual client values. To facilitate EBP in healthcare, clinical practice guidelines can be developed to summarise clinically relevant evidence [9].

Several reviews have been published about the outcomes after radiotherapy and/or chemotherapy in HNC patients (e.g., Frowen and Perry [10]; Jacobi et al. [11]; van der Molen et al. [12]; Paleri et al. [13]; Roe et al. [14]). Most of the reviews focused on selected functional domains in populations with HNC: health-related QoL [15], swallowing [13, 14, 16], and voice and speech [11]. Only the review by van der Molen et al. [12] covered a wider range of functional outcomes in patients with advanced HNC, including swallowing, mouth opening, nutrition, pain, and QoL. Further, the purpose of some studies was to provide evidence-based clinical guidelines (e.g., Paleri et al. [13]) and they did not perform systematic literature searches in line with the PRISMA guidelines [17]. As such, even though a number of reviews have been published over the last ten years, a comprehensive updated systematic review is needed that includes all functional domains affected by radiotherapy and/or chemotherapy in patients with head and neck carcinoma.

A systematic review was conducted to describe the effects of radiotherapy and/or chemotherapy on functions of the upper aerodigestive tract in patients with HNC and examined the evidence of interventions by speech pathologists.

\section{Methods}

A systematic literature search was performed by two independent reviewers. The electronic biomedical databases PubMed and Embase were used (search period from start of database until 5 May 2016). The searches were limited to English language publications. In PubMed the MeSH terms larynx or hypopharynx were combined with all MeSH terms related to head and neck neoplasms (Table 1). Next, the results were linked to all MeSH terms for chemotherapy or radiotherapy, after which the outcome was combined with all $\mathrm{MeSH}$ terms found for dysfunctions of the upper aerodigestive tract and limited with adults +19 years. The exact syntax of the literature search is presented in Table 1.

In Embase the thesaurus terms larynx or hypopharynx were linked to neoplasm and radiotherapy or chemotherapy. Next, the search outcome was combined with the following terms: dysphagia, speech, speech disorder, voice, dysphonia, xerostomia, quality of life, dysarthria, or trismus (see Table 1).

To identify the most recent publications, the search was complemented by free text words in PubMed and Embase (for the period after April 2015 until May 2016). Truncation symbols and wildcards were used to search for variant forms of words or word extensions: Laryn*, pharyn* or hypopharyn* were combined with cancer*, neoplasm*, tumour $^{*}$ or carcinoma* . Furthermore, these free text words were combined with radiation ${ }^{*}$, radiotherap ${ }^{*}$, chemotherap ${ }^{*}$, adjuvant therap ${ }^{*}$ or radiochemotherap ${ }^{*}$ and, finally, combined with deglut ${ }^{*}$, swallow $^{*}$, dysphag $^{*}$, speech $^{*}$, voic $^{*}$, articulat $^{*}$, dysphon $^{*}$, quality of life ${ }^{*}$, xerostom ${ }^{*}$, dysarthr ${ }^{*}$ or anarthr*.

Only articles presenting both pre- and postintervention data of the upper aerodigestive tract functions of the participants were included. Review articles and studies with a population sample of less than 20 patients were excluded, as well as experiments on animals or articles not published in English. Furthermore, studies published before 1990, case reports, expert opinions, and articles describing combinations of therapy including surgical interventions were excluded.

Final decisions on inclusion were made based on the original articles by consensus between two expert reviewers in accordance with the PRISMA statement [17]. The reference lists of all the included articles were searched for additional literature. Next, the standard quality assessment QualSyst as described by Kmet et al. [18] was performed in order to evaluate the methodological strength and weaknesses of the included studies. All ratings were performed by two independent reviewers. After consensus, studies with poor methodology scores $(<50 \%)$ were excluded. All included articles were classified according to the Australian National Health and Medical Research Council (NHMRC) Evidence Hierarchy [19]. Data were retrieved from all studies and tabulated; further details on selected speech pathology interventions were summarised separately.

\section{Results}

Using MeSH or thesaurus terms, 304 articles were located in PubMed and 201 in Embase. Free text word searches resulted in another 148 articles in PubMed and 397 in Embase. The combination of these searches, without overlap, yielded 947 articles. Figure 1 outlines the PRISMA reviewing process according to Moher et al. [20]. Sixty articles met all inclusion criteria.

Table 2 shows the outcomes of the QualSyst critical appraisal tool by Kmet et al. [18]. As all studies had sufficient methodological quality, no further studies were excluded; the overall methodological quality ranged from adequate to good with 0 studies ranked as poor, 3 studies as adequate, 3 studies as good, and 54 studies as strong. Based on the NHMRC 
TABLE 1: Search strategies per literature database.

\begin{tabular}{|c|c|c|c|}
\hline & Database and search terms & Limits & $\begin{array}{c}\text { Number of } \\
\text { records }\end{array}$ \\
\hline Subject headings & $\begin{array}{l}\text { Embase: (larynx/OR pharynx/OR hypopharynx/) AND (neoplasm/OR larynx } \\
\text { disorder/OR pharynx disorder/OR larynx cancer/OR larynx carcinoma/OR } \\
\text { pharynx cancer/OR pharynx carcinoma/) } \\
\text { AND (radiotherapy/OR chemotherapy/OR chemoradiotherapy/OR adjuvant } \\
\text { therapy/OR drug therapy/) } \\
\text { AND (speech sound disorder OR speech/or speech disorder/OR swallowing/OR } \\
\text { dysphagia/OR dysphonia/OR voice disorder/OR aphonia/OR speech } \\
\text { intelligibility/OR xerostomia/OR dysarthria/OR esophagus speech/OR larynx } \\
\text { prosthesis/OR trismus/OR "quality of life"/) }\end{array}$ & English & 201 \\
\hline Subject headings & 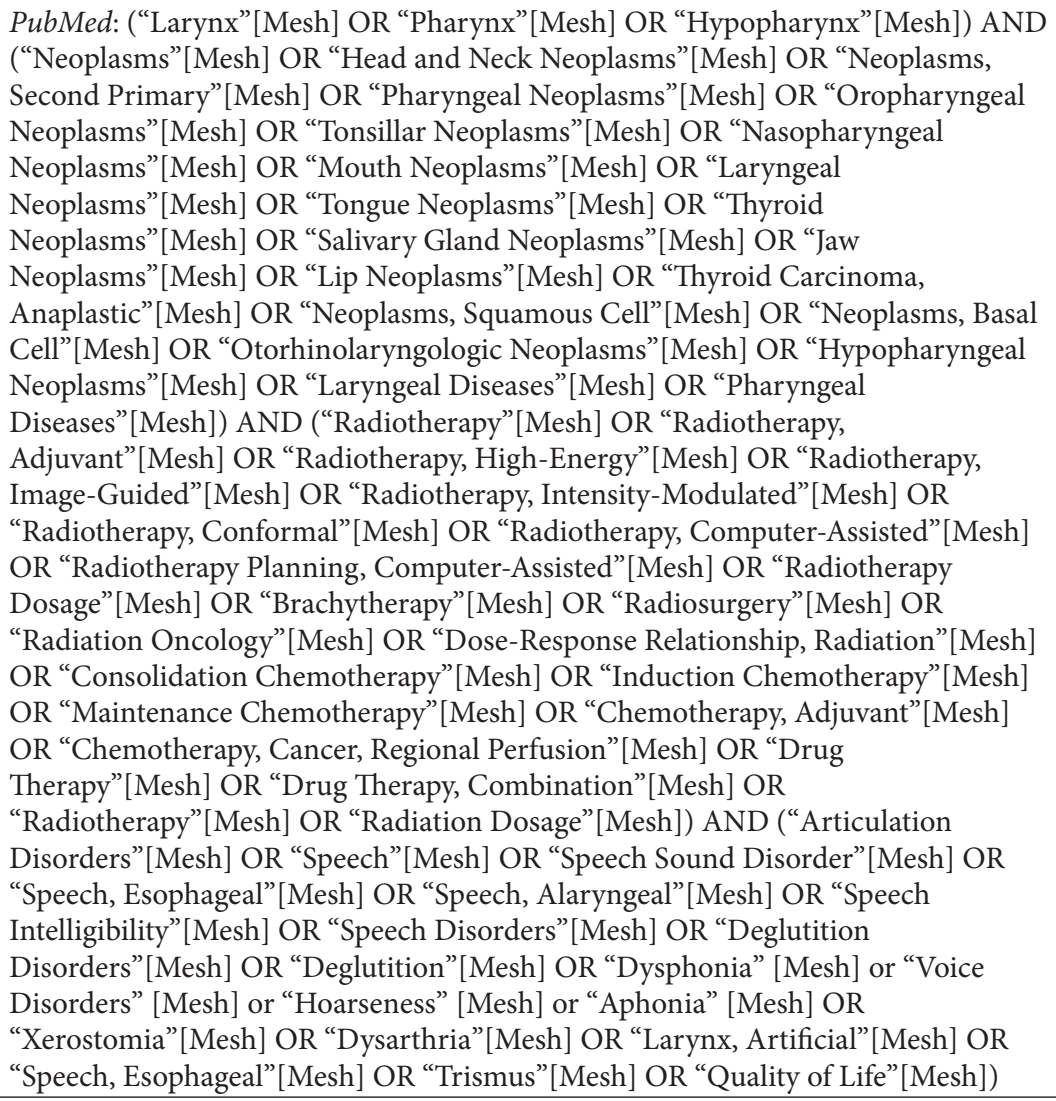 & $\begin{array}{l}\text { Adult: } 19+\text { years } \\
\text { English }\end{array}$ & 304 \\
\hline Free text & 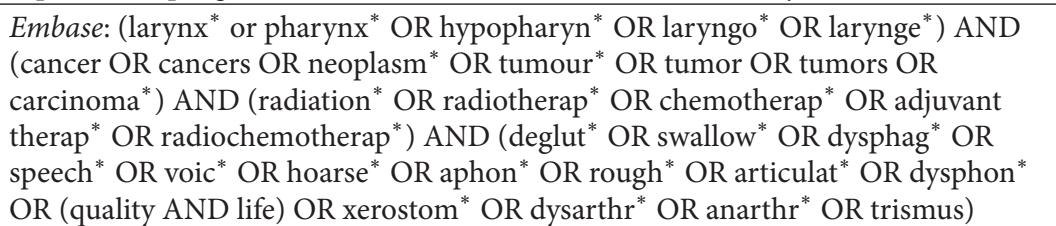 & $\begin{array}{l}\text { Publication date: } \\
\text { last year }\end{array}$ & 397 \\
\hline Free text & PubMed: As per Embase Free Text & $\begin{array}{l}\text { Publication date: } \\
\text { from } 2015 / 05 / 05 \text { to } \\
2016 / 05 / 05\end{array}$ & 148 \\
\hline
\end{tabular}

Evidence Hierarchy [19], 6 studies were classified as level II evidence and 54 studies as level III evidence.

All 60 studies focused on different functions of the upper aerodigestive tract following radiotherapy and/or chemotherapy for HNC. The following constructs were evaluated across the different studies: communication (voice and speech), functions of the digestive tract (oral intake, weight loss, dysphagia, trismus, xerostomia, and tube dependency), QoL, and overall survival rates.

Table 3 provides a summary of the 60 retrieved observational and intervention studies that met the inclusion criteria. The first column presents the reference of the author(s). The second column represents the number of subjects, the third column represents the etiology of the head and neck 


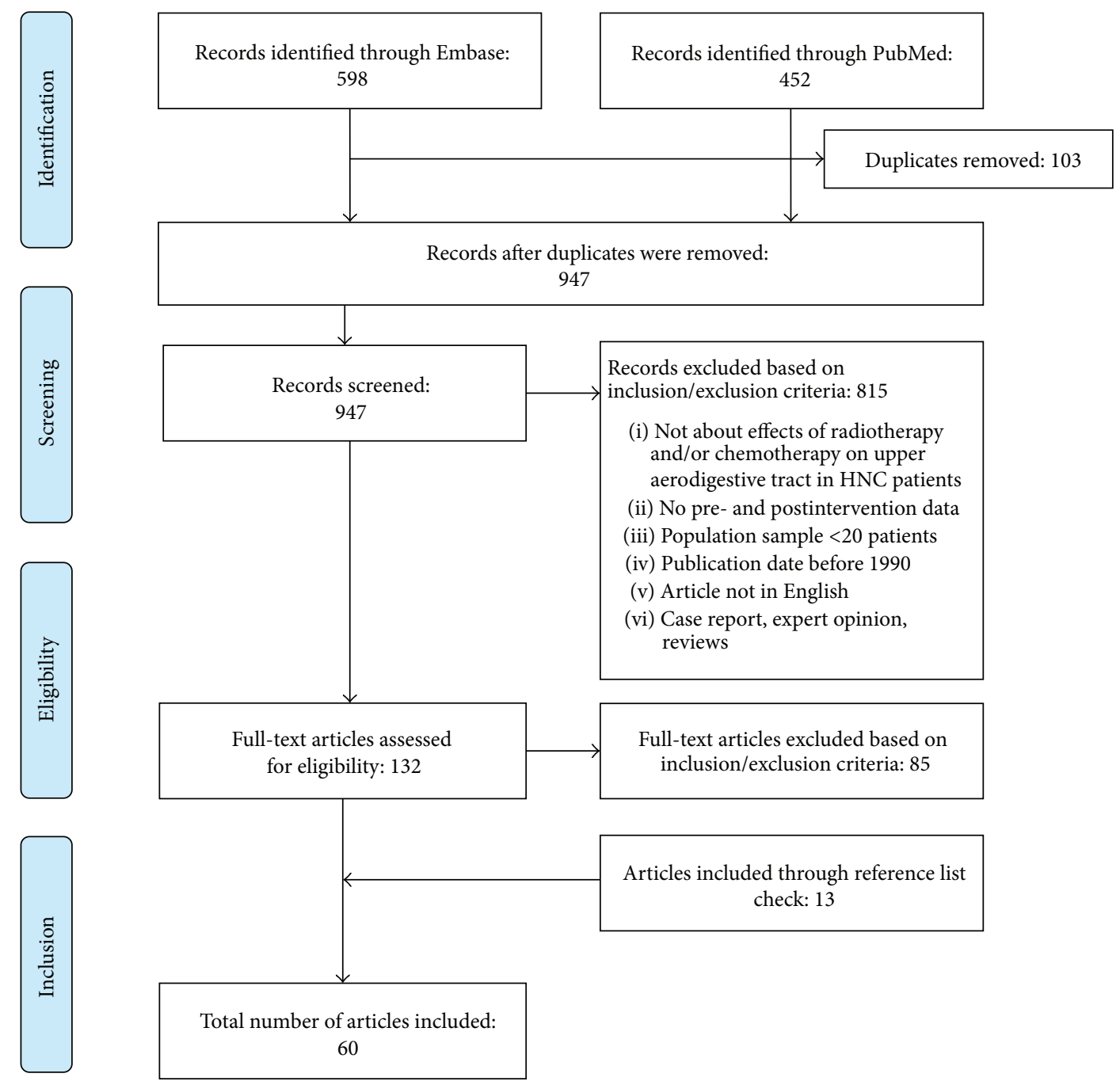

FIGURE 1: PRISMA flowchart.

malignancies, and the 4th column displays the staging of the malignancies. The 5th column shows whether voice and/or speech, digestive tract, and QoL were studied. The 6th and 7th columns show the evaluation techniques and the treatment, respectively. The 8 th column presents the follow-up and the last column describes the author's key findings.

3.1. Voice and/or Speech Function. Twenty-four studies evaluated voice and/or speech function [21-43] with a followup time ranging from 1-month follow-up [42] to ten-year follow-up [43]. Most studies included patients with laryngeal tumors only; however 11 studies [22, 27, 29, 30, 33-37, 44] also included nonlaryngeal tumors. Seventeen studies [21, 23, 25, $26,28,30-32,34-36,38-43$ ] included patients with low-grade tumors (i.e., T1 and T2) and 15 studies included patient with advanced tumors [22, 24, 27, 29-37, 40, 42, 44].

Nine studies [23, 28, 30, 32, 33, 35, 38, 42, 44] used acoustic analysis to evaluate voice quality, six studies [2426, 34, 35, 39] used the Voice Handicap Index, and three studies $[21,38,43]$ used videolaryngostroboscopy. In several studies, either descriptions of how voice quality was evaluated were missing or nonvalidated tools were used (e.g., patients self-reporting or trial-specific questionnaires). Only four studies $[23,31,40,44]$ reported whether the patient received any voice therapy.

All the studies reported good to excellent outcomes for voice quality at long-term follow-up. Some studies specifically reported pre- to posttreatment improvements of voice or speech quality following radiotherapy and/or chemotherapy $[22,23,28]$. However, other studies [36, 40, 42, 44] reported a deterioration after therapy at long-term follow-up. AlMamgani et al. [26] found a better voice outcome in case of single vocal cord irradiation compared with irradiation of the whole larynx. Mittal et al. [37] concluded that radiation with tissue/dose compensation (TDC) improved articulatory outcome compared to radiation without TDC.

3.2. Functions of the Digestive Tract. Forty studies [16, 22, 29, 34-37, 42, 45-76] describe the effects of radiotherapy and/or chemotherapy on the functions of the digestive tract and used 
TABLE 2: Methodological quality based on QualSyst critical appraisal tool by Kmet et al. 2004 [18] and NHMRC 1999 [19] evidence level of included articles.

\begin{tabular}{|c|c|c|c|}
\hline Reference & Kmet score (\%) & Methodological quality $^{1}$ & NHMRC level of evidence $^{2}$ \\
\hline Aaltonen et al. 2014 [21] & $25 / 28(89 \%)$ & Strong & II \\
\hline Ackerstaff et al. 2009 [22] & $22 / 28(79 \%)$ & Good & II \\
\hline Agarwal et al. 2009 [23] & $19 / 24(79 \%)$ & Good & III-2 \\
\hline Agarwal et al. 2011 [45] & $17 / 20(85 \%)$ & Strong & III-3 \\
\hline Akst et al. 2004 [46] & $17 / 20(85 \%)$ & Strong & III-3 \\
\hline Al-Mamgani et al. 2012 [24] & $19 / 20(95 \%)$ & Strong & III-3 \\
\hline Al-Mamgani et al. 2012 [47] & $21 / 22(95 \%)$ & Strong & III-3 \\
\hline Al-Mamgani et al. 2013 [25] & $21 / 22(95 \%)$ & Strong & III-3 \\
\hline Al-Mamgani et al. 2015 [26] & $21 / 22(95 \%)$ & Strong & III-3 \\
\hline Bansal et al. 2004 [27] & $14 / 24(58 \%)$ & Adequate & III-3 \\
\hline Bibby et al. 2008 [28] & $18 / 22(82 \%)$ & Strong & III-2 \\
\hline Bottomley et al. 2014 [78] & $24 / 28(86 \%)$ & Strong & II \\
\hline Buchbinder et al. 1993 [48] & $14 / 26(54 \%)$ & Adequate & III-1 \\
\hline Caudell et al. 2010 [49] & $21 / 22(95 \%)$ & Strong & III-3 \\
\hline Christianen et al. 2015 [50] & $21 / 22(95 \%)$ & Strong & III-3 \\
\hline Cohen et al. 2006 [51] & $19 / 20(95 \%)$ & Strong & III-3 \\
\hline Dornfeld et al. 2007 [29] & $17 / 22(77 \%)$ & Strong & III-3 \\
\hline Dijkstra et al. 2007 [52] & $19 / 22(86 \%)$ & Strong & III-3 \\
\hline Feng et al. 2007 [53] & $19 / 22(86 \%)$ & Strong & III-3 \\
\hline Feng et al. 2010 [54] & $20 / 20(100 \%)$ & Strong & III-3 \\
\hline Frowen et al. 2010 [16] & $22 / 22(100 \%)$ & Strong & III-2 \\
\hline Haderlein et al. 2014 [55] & $17 / 20(85 \%)$ & Strong & III-3 \\
\hline Hutcheson et al. 2014 [56] & $18 / 20(90 \%)$ & Strong & III-3 \\
\hline Jacobi et al. 2016 [30] & $17 / 18(94 \%)$ & Strong & III-3 \\
\hline Karlsson et al. 2015 [31] & $26 / 28(93 \%)$ & Strong & II \\
\hline Karlsson et al. 2016 [32] & $18 / 20(90 \%)$ & Strong & III-3 \\
\hline Kazi et al. 2008 [33] & $17 / 20(85 \%)$ & Strong & III-2 \\
\hline Kerr et al. 2015 [34] & $19 / 20(95 \%)$ & Strong & III-2 \\
\hline Kotz et al. 2012 [57] & $24 / 28(86 \%)$ & Strong & II \\
\hline Kraaijenga et al. 2014 [35] & $19 / 20(95 \%)$ & Strong & III-3 \\
\hline Kumar et al. 2014 [58] & $19 / 20(95 \%)$ & Strong & III-2 \\
\hline Lazarus et al. 2014 [36] & $19 / 20(95 \%)$ & Strong & III-3 \\
\hline List et al. 1999 [59] & $15 / 18(83 \%)$ & Strong & III-3 \\
\hline McLaughlin et al. 2010 [60] & $19 / 20(95 \%)$ & Strong & III-3 \\
\hline Mittal et al. 2001 [37] & $16 / 20(80 \%)$ & Strong & III-3 \\
\hline Murry et al. 1998 [61] & $11 / 20(55 \%)$ & Adequate & III-3 \\
\hline Niedzielska et al. 2010 [38] & $17 / 20(85 \%)$ & Strong & III-2 \\
\hline Nourissat et al. 2010 [62] & $23 / 26(88 \%)$ & Strong & III-3 \\
\hline Ottoson et al. 2014 [63] & $19 / 22(86 \%)$ & Strong & III-3 \\
\hline Pauli et al. 2013 [64] & $19 / 22(86 \%)$ & Strong & III-3 \\
\hline Pauloski et al. 2006 [65] & $18 / 20(90 \%)$ & Strong & III-3 \\
\hline Rademaker et al. 2003 [66] & $17 / 20(85 \%)$ & Strong & III-3 \\
\hline Remmelts et al. 2013 [39] & $18 / 20(90 \%)$ & Strong & III-3 \\
\hline Salama et al. 2008 [67] & $17 / 20(85 \%)$ & Strong & III-3 \\
\hline Sanguineti et al. 2014 [40] & $19 / 20(95 \%)$ & Strong & III-3 \\
\hline Scrimger et al. 2007 [68] & $18 / 20(90 \%)$ & Strong & III-3 \\
\hline Spector et al. 1999 [41] & $17 / 22(77 \%)$ & Good & III-3 \\
\hline
\end{tabular}


TABLE 2: Continued.

\begin{tabular}{|c|c|c|c|}
\hline Reference & Kmet score (\%) & Methodological quality $^{1}$ & NHMRC level of evidence $^{2}$ \\
\hline Starmer et al. 2014 [69] & $18 / 20(90 \%)$ & Strong & III-3 \\
\hline Stenson et al. $2010[70]$ & $16 / 20(80 \%)$ & Strong & III-3 \\
\hline Strigari et al. 2010 [71] & $17 / 20(85 \%)$ & Strong & III-3 \\
\hline Tuomi et al. 2015 [42] & $18 / 20(90 \%)$ & Strong & III-2 \\
\hline Urdaniz et al. 2005 [77] & $18 / 20(90 \%)$ & Strong & III-2 \\
\hline Vainshtein et al. 2015 [72] & $20 / 24(83 \%)$ & Strong & III-3 \\
\hline van der Molen et al. 2011 [73] & $24 / 26(92 \%)$ & Strong & II \\
\hline van der Molen et al. 2012 [44] & $16 / 20(80 \%)$ & Strong & III-3 \\
\hline van der Molen et al. 2013 [74] & $19 / 20(95 \%)$ & Strong & III-3 \\
\hline Verdonck-de Leeuw et al. 1999 [43] & $18 / 20(90 \%)$ & Strong & III-2 \\
\hline Verdonck-de Leeuw et al. 2014 [79] & $16 / 20(80 \%)$ & Strong & III-2 \\
\hline Vlacich et al. 2014 [75] & $18 / 20(90 \%)$ & Strong & III-3 \\
\hline Wilson et al. 2011 [76] & $18 / 20(90 \%)$ & Strong & III-3 \\
\hline
\end{tabular}

${ }^{1}$ Methodological quality: strong $>80 \%$; good $60-79 \%$; adequate $50-59 \%$; poor $<50 \%$.

${ }^{2}$ NHMRC evidence hierarchy designates the following hierarchy: level I (evidence obtained from a systematic review of all relevant RCTs), level II (evidence obtained from at least one properly designed RCT), level III-1 (evidence obtained from well-designed pseudo-RCTs [alternate allocation or some other method]), level III-2 (evidence obtained from comparative studies with concurrent controls and allocation not randomised [cohort studies], case control studies, or interrupted time series with a control group), level III-3 (evidence obtained from comparative studies with historical control, two or more single-arm studies, or interrupted time series without a parallel control group), and level IV (evidence obtained from case series, either posttest or pretest and posttest).

a variety of outcome measures. Of these 40 studies, 16 studies $[16,35,37,45,49,53,54,56,58,63,65,67,69,70,73,74]$ used videofluoroscopy to measure physiological changes in swallowing function. Eight studies $[29,35,46,47,49,55$, $60,75]$ used feeding tube dependency as a (dichotomous) outcome, whereas seven studies $[35,46,57,65,66,69,73]$ described the level of oral intake in more detail. Only four studies $[35,36,56,76]$ used a condition specific validated measure for swallowing disorders (e.g., MDADI).

With regard to nutritional status, five studies $[29,60,62$, $63,73]$ used the body mass index as an outcome or reported specifically on weight gain or loss. Seven studies $[35,36,48$, $52,64,73,74]$ used the presence of trismus as an outcome by reporting on the maximum distance of mouth opening. Saliva flow (as a measure of xerostomia) was used in four studies $[36,37,68,71]$.

Follow-up times in these studies range from immediately after therapy [62] to 6 years after therapy [35], describing both low stage tumors and more advanced tumors. Thirtytwo studies used the TNM-classification system, stage was described in six other studies, and the remaining two studies did not report on tumor stage or grade. However, it was unclear whether the clinical TNM-score or the pathological TNM-score was used to describe the severity of the disease. Eight studies $[16,35,46,48,52,56,57,69,73,74]$ described whether the patients received functional treatment (by a speech pathologist); the remainder of the articles did not mention whether the patient received any additional treatment.

Nine studies reported impaired swallowing function following radiotherapy and/or chemotherapy $[36,45,50,54-$ $56,69,75,76]$.

Five studies $[16,51,59,61,66]$ showed that swallowing was least affected at baseline, worst immediately following posttreatment ( $0-3$ months after treatment), and improved by
6-12 months after treatment and later. However, swallowing usually did not return to pretreatment functioning level. In four studies $[49,53,58,74]$, a relation between dosevolume, dysphagia, and aspiration was found. Caudell et al. [49] showed that a mean radiation dosage $>41 \mathrm{~Gy}$ with $>24 \%$ volume of the larynx being radiated was associated with increased percutaneous endoscopic gastrostomy (PEG) dependency and aspiration. Akst et al. [46] correlated advanced tumor stage and age $>60$ years with a deterioration of swallowing.

Ackerstaff et al. [22] demonstrated improved oral intake postradiotherapy and/or chemotherapy. Stenson et al. [70] stated that weight remained unchanged after treatment (via oral route), whereas Nourissat et al. [62] described a mean weight loss of $2.2 \mathrm{~kg}$ posttreatment.

3.3. QoL. Twenty-five studies $[22,24,25,27-29,31,32$, $35,36,42,44,47,51,53,55,59,62,64,68,72,76-79]$ described the short- and long-term effects of treatment for HNC on patients' general QoL. The European Organization for Research and Treatment of Cancer (EORTC) C30questionnaire was used in fifteen studies $[22,24,25,27,31$, $32,35,42,47,55,62,64,77-79]$ and the more HNC specific EORTC H\&N35 was used in thirteen studies [22, 24, 25, 31, 32, $35,36,42,47,64,77-79]$. Other questionnaires that were used included the University of Washington QoL Questionnaire (UWQoL) [53, 68, 72, 76], the Head and Neck QoL or HNQoL $[53,72]$, and the Xerostomia related QoL or XQoL $[68,72]$. Follow-up time for QoL was up to six years after treatment [35], including patients with tumors that were early staged and patients with advanced tumors.

Although three studies [28, 72, 77] demonstrated improvements in QoL, four studies [22, 36, 42, 54] reported a decrease in general QoL as a result of radiotherapy and/or 


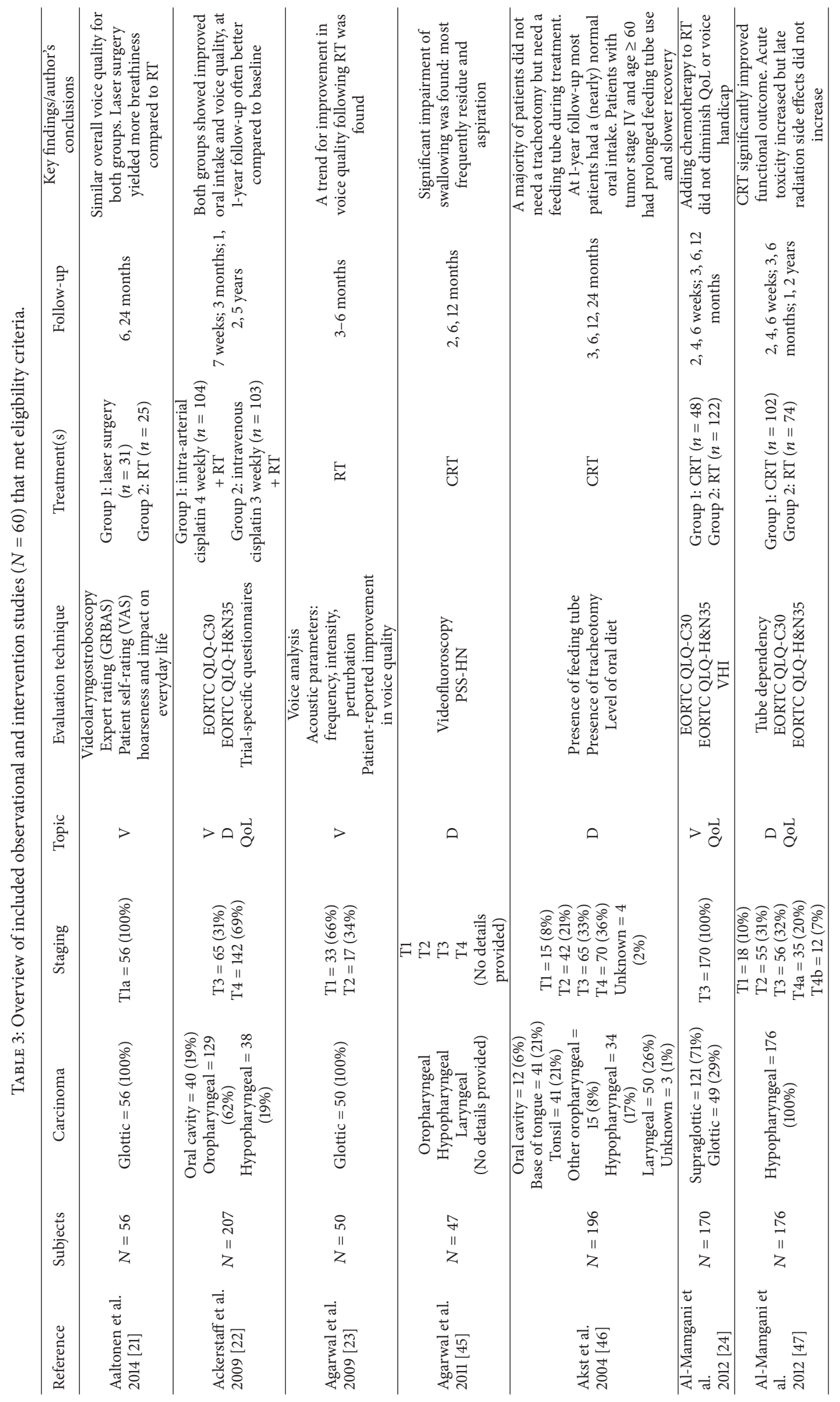




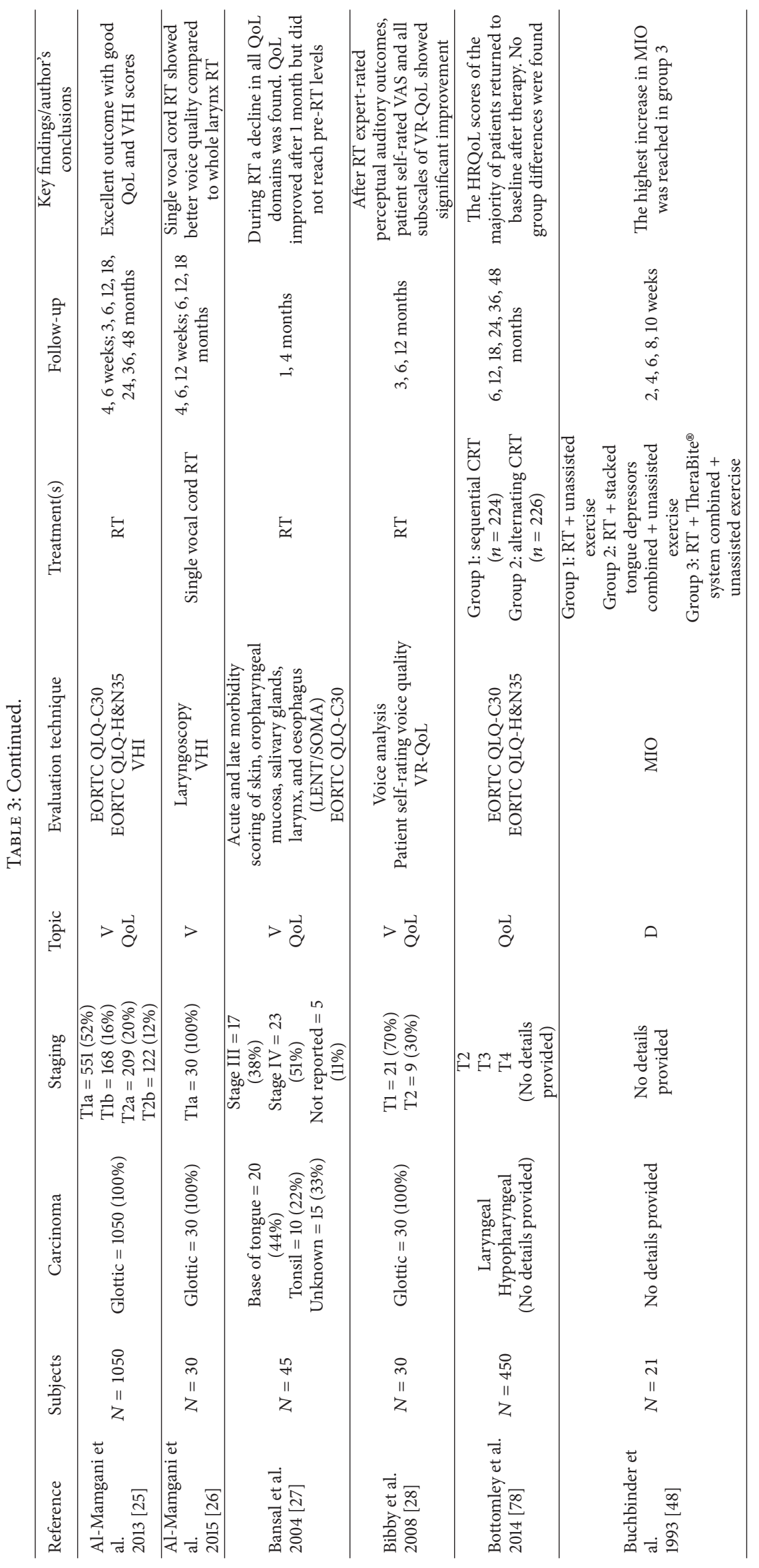




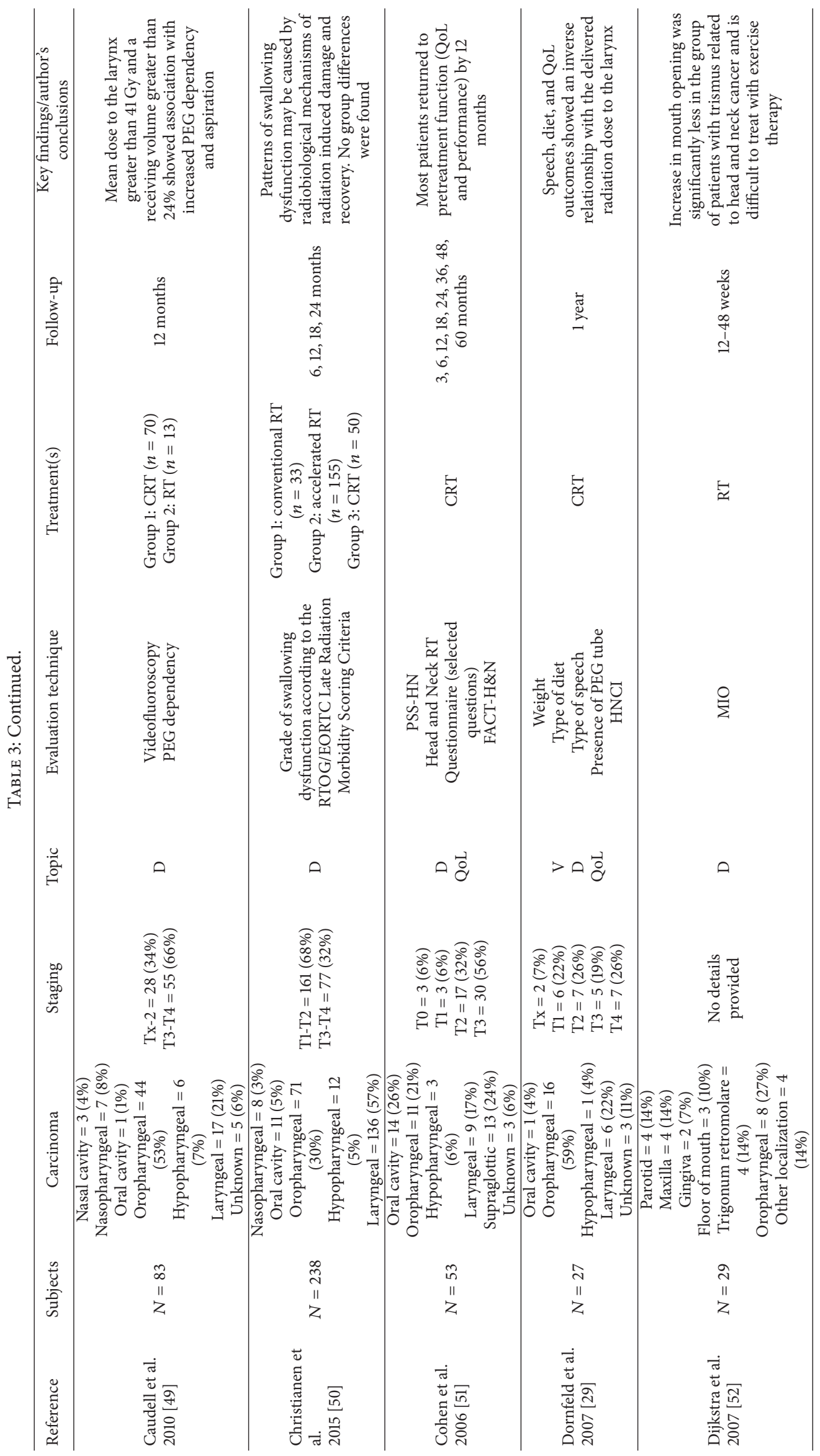




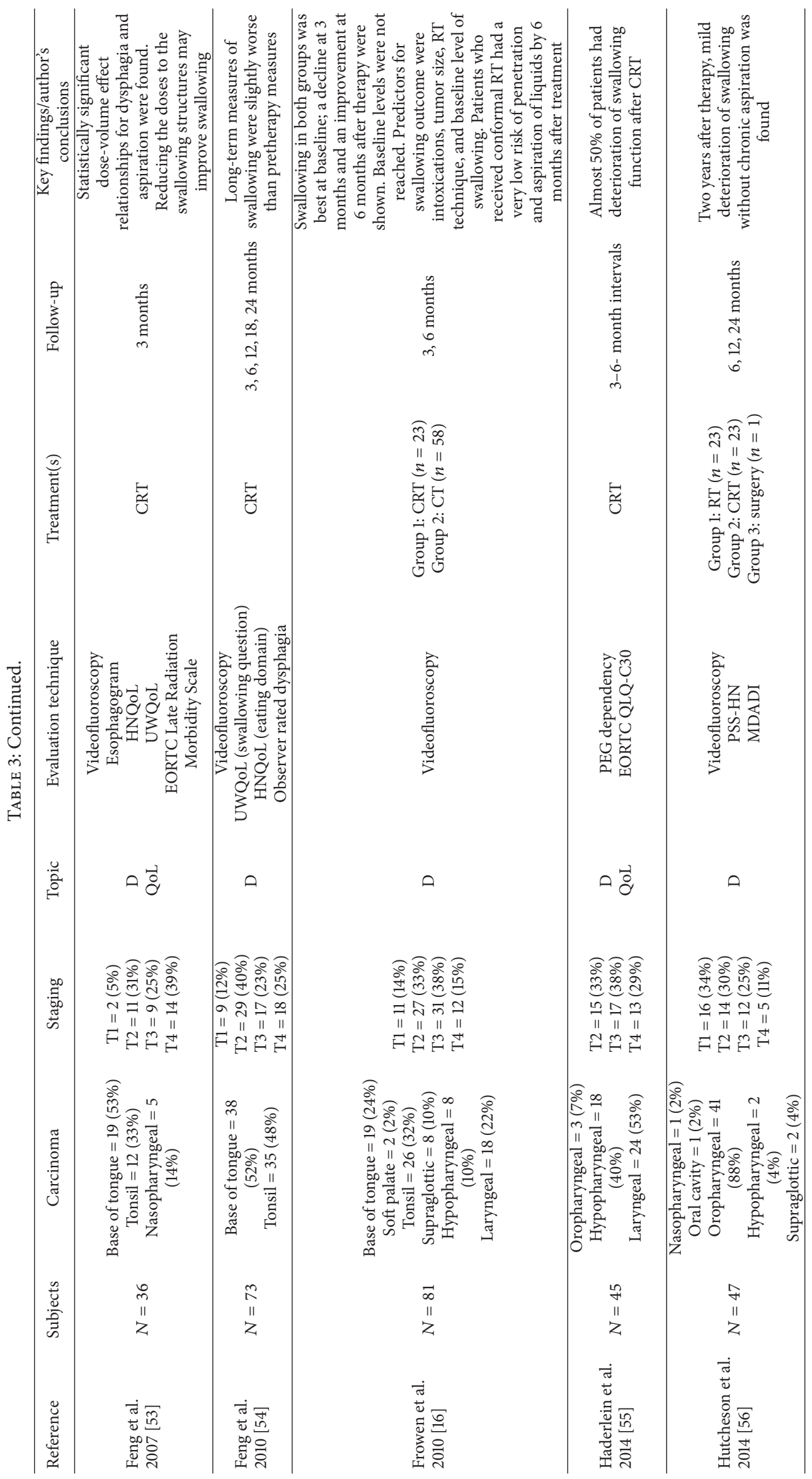




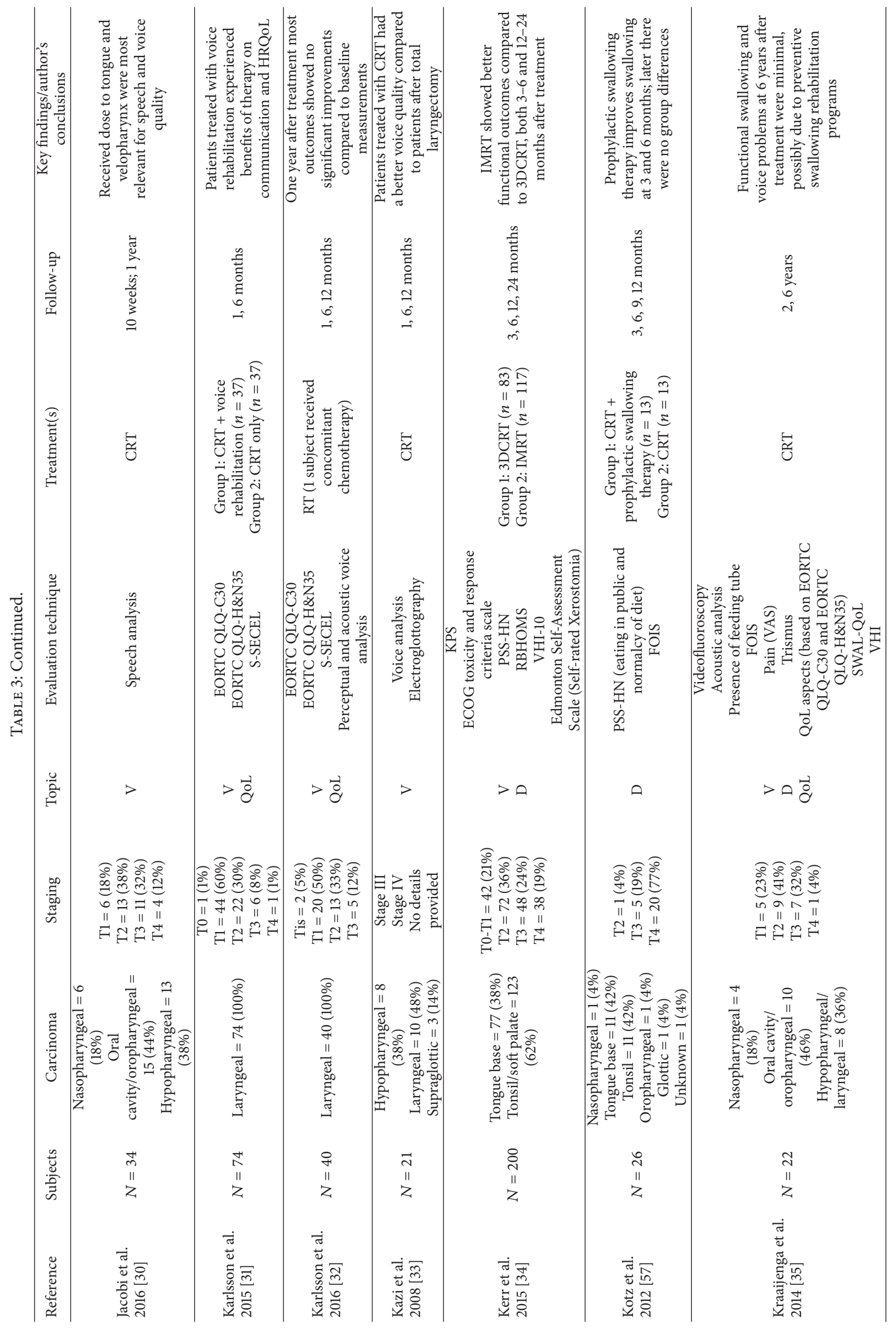




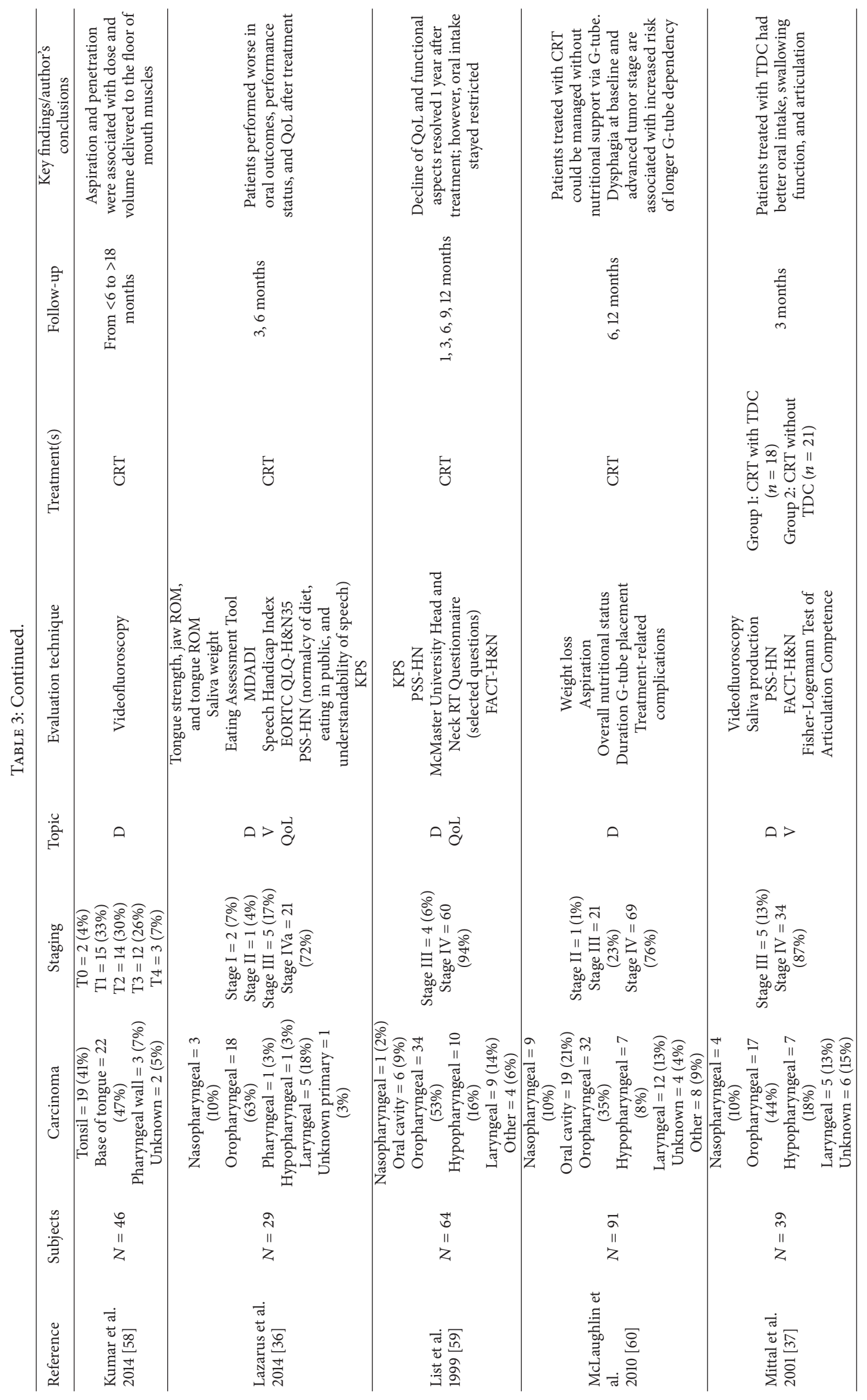




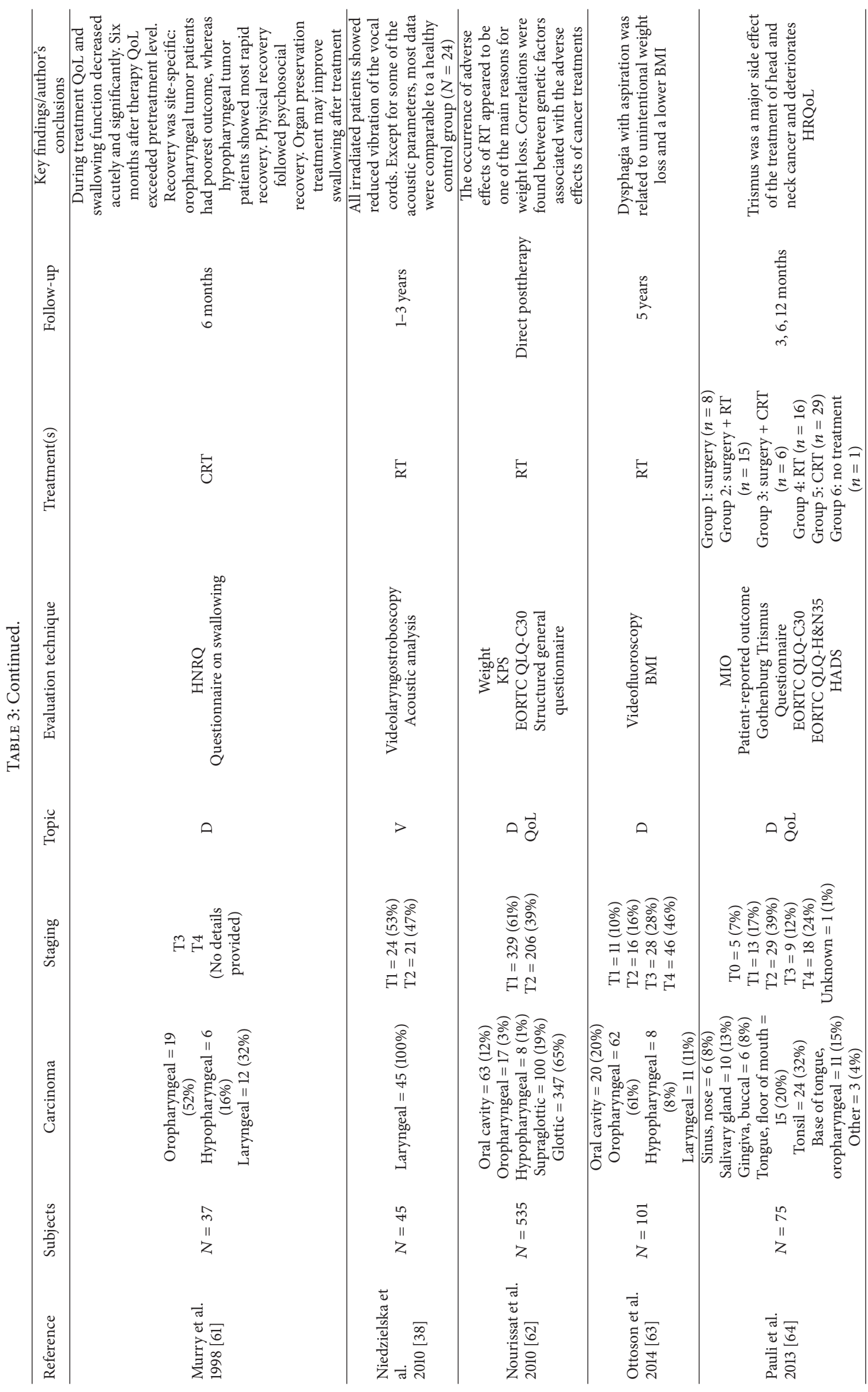




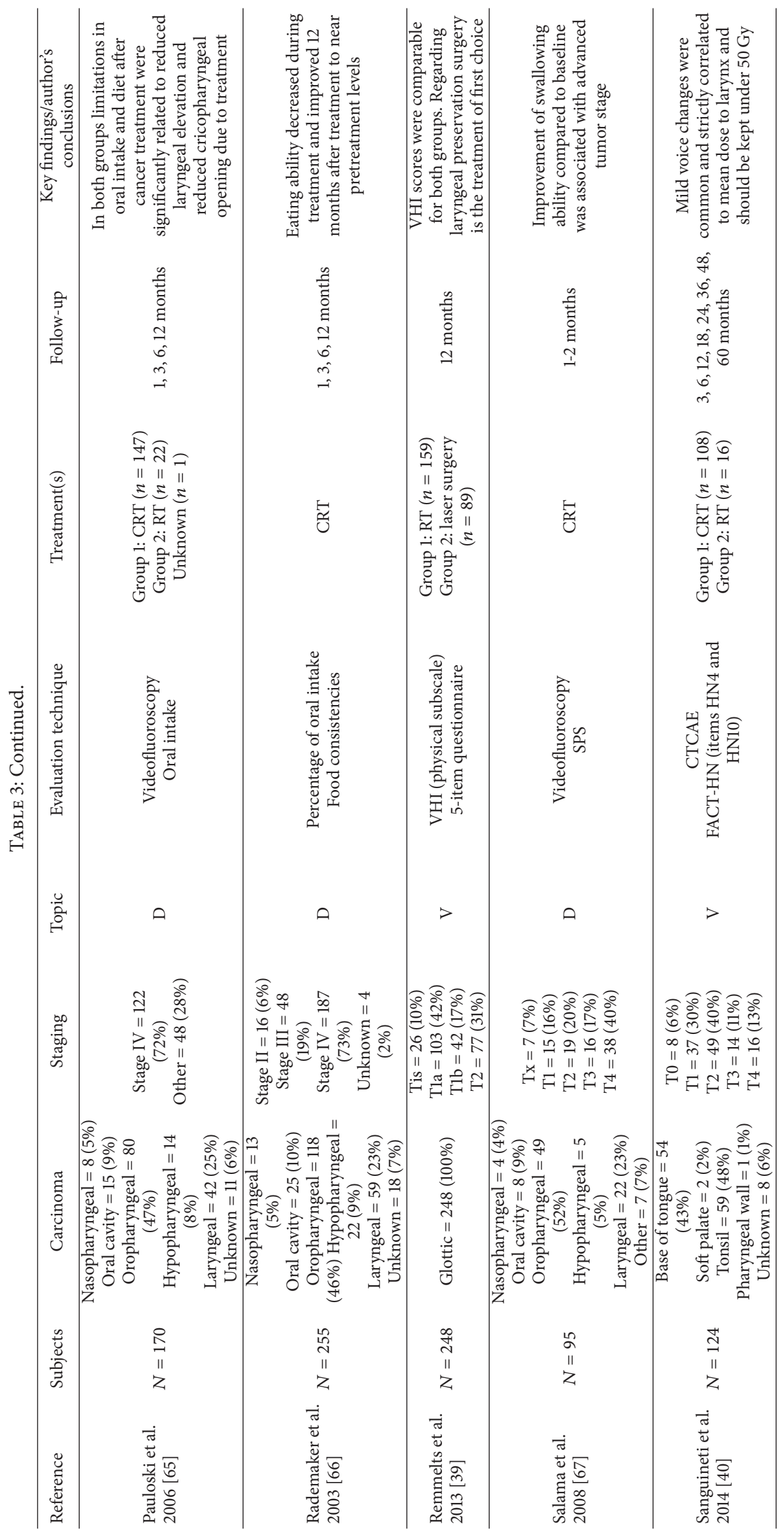




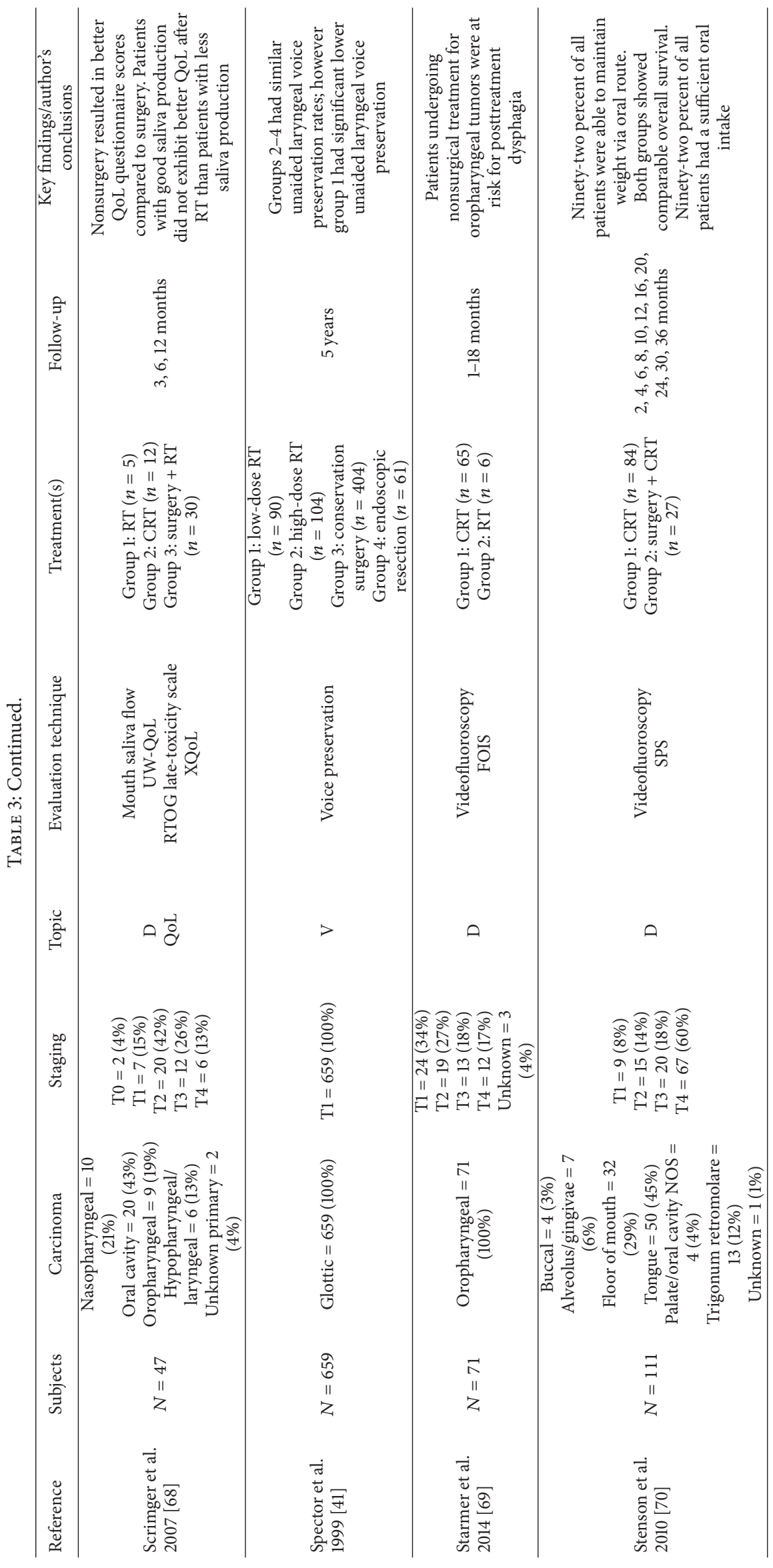




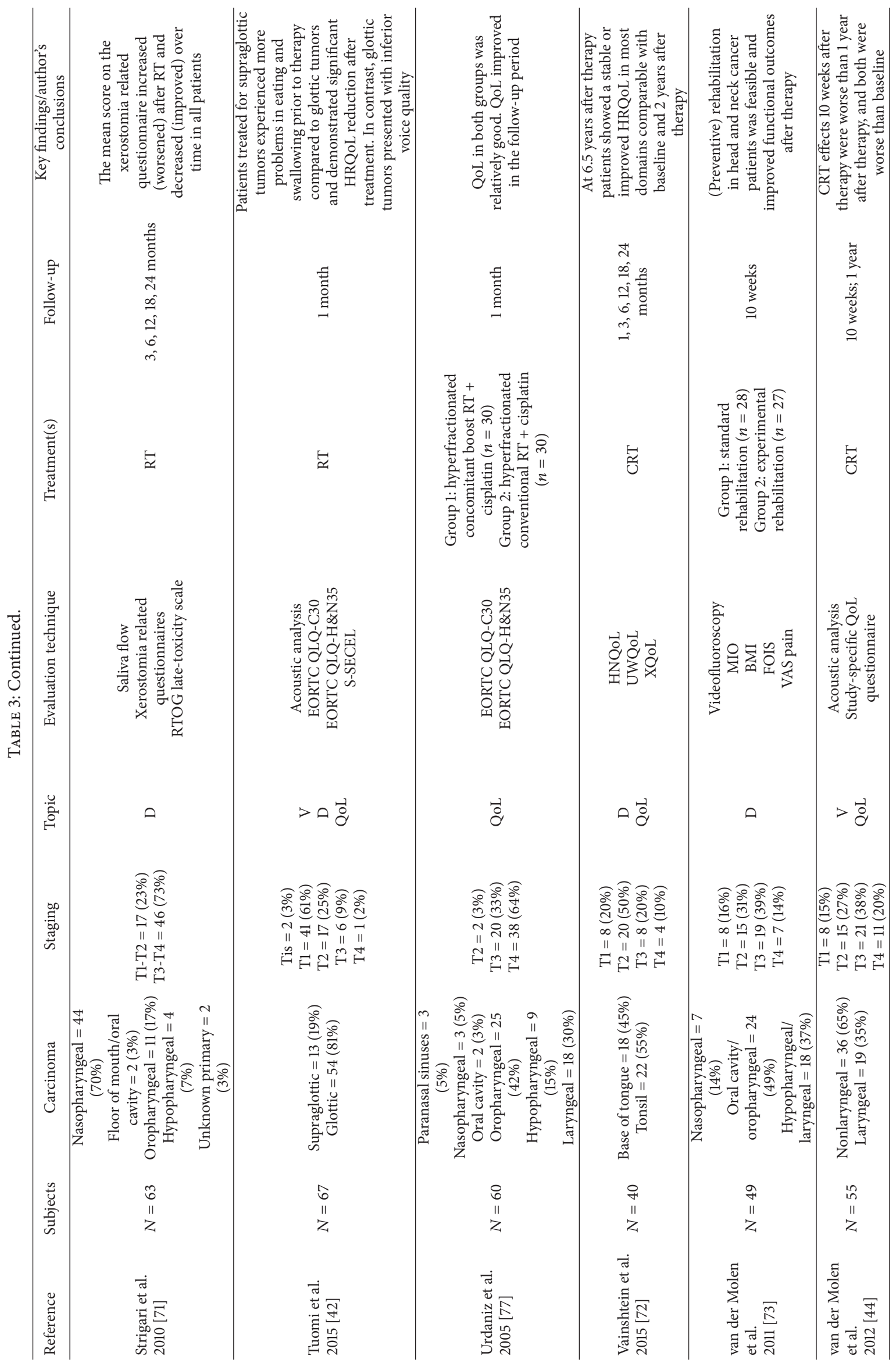




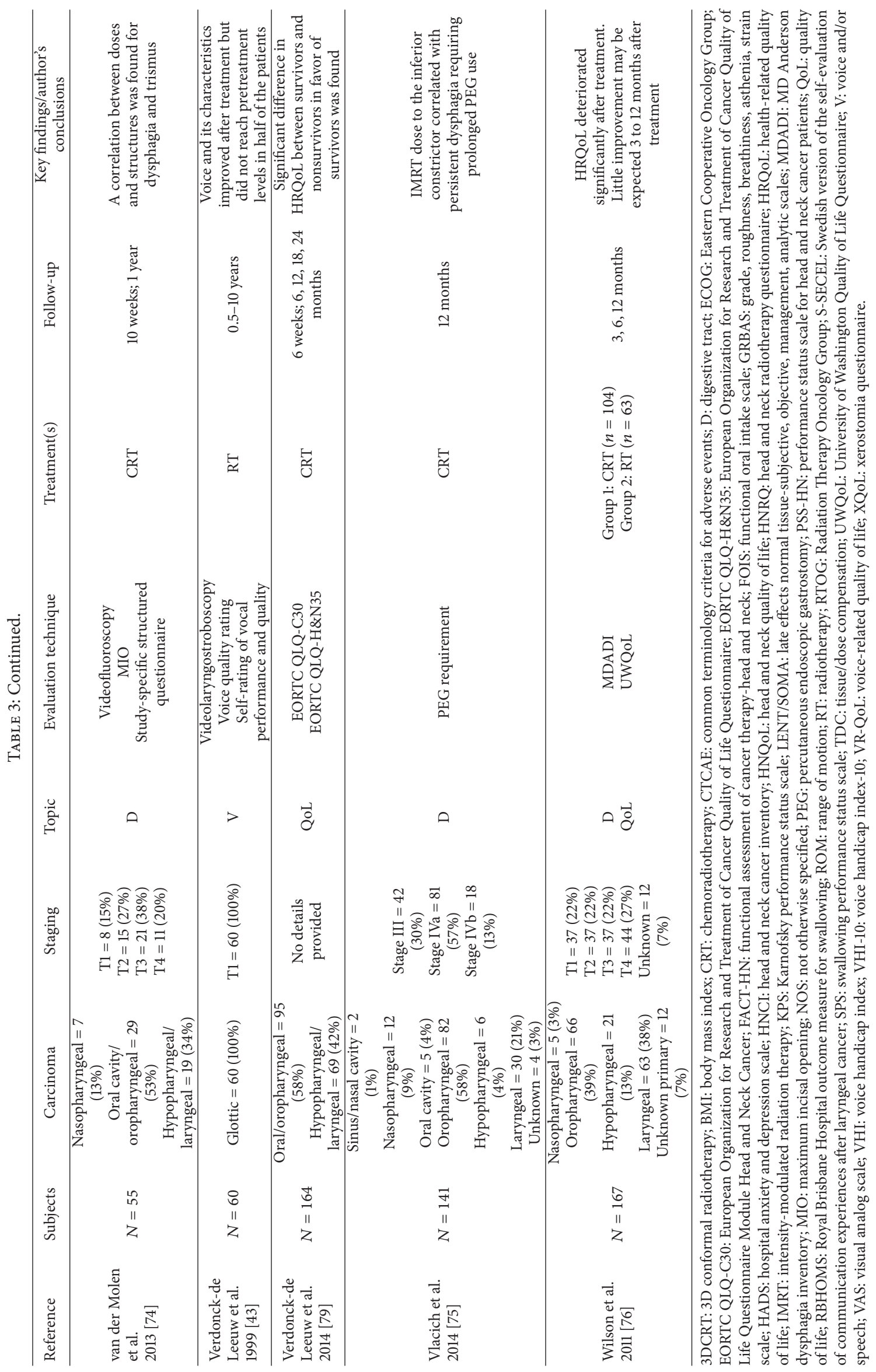


chemotherapy. Bansal et al. [27] found a significant decline in physical, social, and emotional functioning as well as in global health scores following a course of radiotherapy. However, the patients' functional scores improved one month after treatment but did not reach pretreatment levels. The health-related QoL (HRQoL) scores of the majority of patients in the Bottomley et al. [78] study returned to baseline at 48-month follow-up. These findings support the findings of Ackerstaff et al. [22], Cohen et al. [51], Karlsson et al. [32], List et al. [59], and Wilson et al. [76], who suggested that HRQoL deteriorates significantly immediately after treatment, with variable degrees of improvement 3-72 months after treatment.

3.4. Reported (Efficacy of) Speech Pathology Interventions. We assessed the speech pathology interventions against the following criteria: (a) whether a detailed description of the intervention was provided; (b) whether the authors provided a description of treatment duration and intensity; and (c) what the speech pathology intervention outcomes were. The reported efficacy of 14 speech pathology intervention studies aimed at addressing problems in dysphagia, speech, voice, and trismus is summarised in Table 4 .

Of the 60 articles included in this review, 14 studies $[16,23,29,31,35,40,44,46,48,56,57,69,73,74]$ reported whether there was any treatment for the sequelae of radiotherapy and/or chemotherapy. Of these intervention studies, five focused on voice-related problems [23, 31, 35, $40,44]$, two focused on trismus $[48,52]$, seven focused on swallowing disorders [16, 35, 46, 56, 57, 69, 73], and one study reported on both swallowing disorders and trismus [74].

The three studies that investigated the treatment of trismus $[48,52,74]$ presented the most detailed information on what the interventions involved. The study by Dijkstra et al. [52] described a wide variety of trismus-specific therapies, suggesting that most patients received a combination of therapies. The patients in the van der Molen et al. [44] and Kraaijenga et al. [35] studies did not receive any speech therapy. The remainder of the studies reported that patients received speech therapy; however, most of these studies did not provide specific data on treatment duration or intensity. None of the voice-related studies provided information on the specific exercises prescribed to patients except Karlsson et al. [31].

Of the eight studies on swallowing disorders, only Kotz et al. [57] and van der Molen et al. [73] described the prescribed exercises in detail. The aim of the latter study was to compare the effectiveness of experimental rehabilitation to standard rehabilitation in 49 advanced HNC patients. The authors concluded that preventive rehabilitation is feasible and effective in reducing the extent and/or severity of various functional short-term effects of chemoradiotherapy [74]. This finding is supported by the 6-year follow-up study by Kraaijenga et al. [35]. Kotz et al. [57] described a temporary improvement. These are the only studies that provided detailed information about the speech pathology intervention and reported on the effectiveness of the intervention.

\section{Discussion}

In total, 60 studies met the inclusion criteria. The studies described the effects of radiotherapy and/or chemotherapy on the functions of the upper aerodigestive tract in patients with HNC. The articles yielded by this systematic review vary in their findings regarding tumor characteristics and treatment modalities. As a result of this variability, no statistical pooling was possible. We also set out to investigate the involvement of speech pathologists in treating patients with HNC.

When considering treatment outcomes, voice quality worsened at the start of radiotherapy and/or chemotherapy but eventually improved after therapy finished. Dysphagia can be a major side effect of HNC and its treatment. The high incidence of dysphagia in this study population can cause serious secondary consequences, such as malnutrition, dehydration, an increased risk of aspiration, and, at worst, death [80]. As dysphagia is a common sequela to oncological treatment, early detection and treatment are needed to avoid or minimise serious secondary complications [81].

The general description of the study population in Table 3 shows that there was great variability in both the location of the tumor and the grading/staging, making comparisons of these studies difficult. As the follow-up times varied in each study, the outcomes may be noncomparable. Thus, this review shows that there is a need for more standardised approaches to research in this field.

Additionally, a large range of outcome measures were used, some of which are not validated. This calls into question the reliability of results reported in some of the studies. The use of validated and standardised assessments in future research would provide more robust findings.

When considering the functional outcomes of radiotherapy and/or chemotherapy, one of the most important factors is whether the patient had received voice or swallowing therapy. Interestingly, only 14 of the 60 included studies reported whether the patients received any speech therapy. Thus, in 46 articles functional results, such as voice quality, are presented with no specification of whether the patient received therapy. As some of these studies have a follow-up of $>2$ years, it is fair to assume that patients sought help for voice or swallowing problems. Therefore, the involvement of speech therapy may be underreported, suggesting that the presented outcomes in these studies are biased and raise questions about their reliability.

When information was provided about treatment, only six articles [31, 48, 52, 57, 73, 74] described in detail the treatment intensity as the actual treatment. Furthermore, these studies are the only five that include conclusions about the efficacy of speech therapy in this specific population. In the context of EBP, this finding demonstrates the need for more research into the efficacy of speech pathology interventions for patients with $\mathrm{HNC}$ receiving radiotherapy and/or chemotherapy.

To enable the objective reporting of the effectiveness of radiation and/or chemotherapy, baseline measurements of different aspects of voice quality and swallowing are required. To manage expectations, healthcare professionals and patients need to be made aware that some aspects of both 
TABLE 4: Overview of speech pathology interventions aimed at addressing problems in dysphagia, speech, voice, and trismus $(n=14)$.

\begin{tabular}{|c|c|c|c|c|}
\hline Reference & Topic & $\begin{array}{c}\text { General description of } \\
\text { intervention and treatment } \\
\text { intensity/duration }\end{array}$ & $\begin{array}{l}\text { Description of specific } \\
\text { exercises }\end{array}$ & Conclusions specific to therapy \\
\hline $\begin{array}{l}\text { Agarwal et al. } \\
2009 \text { [23] }\end{array}$ & Voice & $\begin{array}{l}\text { All patients received counseling } \\
\text { and voice therapy by a trained } \\
\text { speech pathologist } \\
\text { No specific data provided on } \\
\text { treatment frequency/intensity }\end{array}$ & $\begin{array}{l}\text { No description of exercises } \\
\text { provided }\end{array}$ & $\begin{array}{l}\text { Forty-seven of } 50 \text { patients } \\
\text { showed compliance to the } \\
\text { therapy. No specific conclusions } \\
\text { of influence of provided therapy } \\
\text { on primary outcomes described }\end{array}$ \\
\hline $\begin{array}{l}\text { Akst et al. } \\
2004[46]\end{array}$ & Swallowing & $\begin{array}{l}\text { Swallowing evaluation and } \\
\text { intervention when clinically } \\
\text { indicated }\end{array}$ & $\begin{array}{l}\text { No description of exercises } \\
\text { provided }\end{array}$ & $\begin{array}{l}\text { No specific conclusions of } \\
\text { influence of provided therapy on } \\
\text { primary outcomes described }\end{array}$ \\
\hline $\begin{array}{l}\text { Buchbinder et al. } \\
1993 \text { [48] }\end{array}$ & Trismus & $\begin{array}{l}\text { Six to } 10 \text { exercise sessions per day } \\
\text { for a } 10 \text {-week period }\end{array}$ & $\begin{array}{c}\text { Group 1: unassisted } \\
\text { exercises: reach maximum } \\
\text { MIO and closing, jaw } \\
\text { motion to left, right, and } \\
\text { protrusively } \\
\text { Group 2: unassisted } \\
\text { exercises: reach maximum } \\
\text { MIO and closing, jaw } \\
\text { motion to left, right, and } \\
\text { protrusively. Stacked } \\
\text { tongue depressors, to } \\
\text { mechanically increase MIO } \\
(5 \times 30 \text { seconds per session }) \\
\text { Group 3: unassisted } \\
\text { exercises: reach maximum } \\
\text { MIO and closing, jaw } \\
\text { motion to left, right, and } \\
\text { protrusively. Combined } \\
\text { with the TheraBite System } \\
(5 \times 30 \text { seconds per session) }\end{array}$ & $\begin{array}{l}\text { The first four weeks no } \\
\text { differences between groups were } \\
\text { found. After week } 4 \text { minimal } \\
\text { improvements in groups } 1 \text { and } 2 \\
\text { were found and group } 3 \text { still } \\
\text { improved. The highest increment } \\
\text { in MIO was reached in group } 3\end{array}$ \\
\hline
\end{tabular}

Physical therapy consisting

$$
\text { of }
$$

(i) Active range of motion

(ii) Hold and relax

(iii) Manual stretching

(iv) Joint distraction

Dijkstra et al.
2007 [52] $\quad$ Trismus $\quad \begin{gathered}\text { Physical therapy for trismus, } \\ \text { median of } 4 \text { sessions }\end{gathered}$

Following therapeutic tools are used in described cohort:

(i) Rubber plugs

(ii) Tong blades

(iii) Dynamic bite opener

(iv) TheraBite System

\begin{tabular}{|c|c|c|c|c|}
\hline $\begin{array}{l}\text { Frowen et al. } \\
2010[16]\end{array}$ & Swallowing & $\begin{array}{l}\text { All patients were seen by a } \\
\text { speech pathologist as an aspect of } \\
\text { regular care }\end{array}$ & $\begin{array}{l}\text { No description of exercises } \\
\text { provided }\end{array}$ & $\begin{array}{l}\text { No specific conclusions of } \\
\text { influence of provided therapy on } \\
\text { primary outcomes described }\end{array}$ \\
\hline $\begin{array}{l}\text { Hutcheson et al. } \\
2014[56]\end{array}$ & Swallowing & $\begin{array}{l}\text { All patients received prophylactic } \\
\text { swallowing therapy to avoid } \\
\text { nothing by mouth periods } \\
\text { during treatment } \\
\text { No specific data provided on } \\
\text { treatment frequency/intensity }\end{array}$ & $\begin{array}{l}\text { Targeted swallowing } \\
\text { exercises }\end{array}$ & $\begin{array}{l}\text { No specific conclusions of } \\
\text { influence of provided therapy on } \\
\text { primary outcomes described }\end{array}$ \\
\hline $\begin{array}{l}\text { Karlsson et al. } \\
2015[31]\end{array}$ & Voice & $\begin{array}{c}\text { Group 1: voice therapy group } \\
\text { received } 10 \times 30 \text {-minute sessions } \\
\text { over } 10 \text { weeks } \\
\text { Group 2: vocal hygiene group: } 1 \\
\text { session for vocal hygiene advice }\end{array}$ & $\begin{array}{l}\text { Group 1: voice therapy } \\
\text { consisting of relaxation, } \\
\text { respiration, posture, and } \\
\text { phonation exercises } \\
\text { Group 2: vocal hygiene } \\
\text { advice }\end{array}$ & $\begin{array}{l}\text { Patients treated with voice } \\
\text { therapy experienced greater } \\
\text { improvements compared to } \\
\text { patients that only received vocal } \\
\text { hygiene advice. Group } 1 \text { showed } \\
\text { a significant better functional } \\
\text { communication and HRQoL }\end{array}$ \\
\hline
\end{tabular}
communication and HRQoL
MIO increases significantly after physical therapy. History of HNC decreases the effect of physical therapy, compared to other trismus patients 
TABle 4: Continued.

\begin{tabular}{|c|c|c|c|c|}
\hline Reference & Topic & $\begin{array}{c}\text { General description of } \\
\text { intervention and treatment } \\
\text { intensity/duration }\end{array}$ & $\begin{array}{l}\text { Description of specific } \\
\text { exercises }\end{array}$ & Conclusions specific to therapy \\
\hline $\begin{array}{l}\text { Kotz et al. } \\
2012[57]\end{array}$ & Swallowing & $\begin{array}{c}\text { Group 1: weekly treatment by } \\
\text { speech pathologist and daily } 3 \times \\
10 \text { home sessions of exercises. } \\
\text { Group 2: swallowing assessment } \\
\text { and treatment if necessary after } \\
\text { treatment }\end{array}$ & $\begin{array}{l}\text { Group 1: prophylactic } \\
\text { swallowing therapy } \\
\text { consisting of effortful } \\
\text { swallow, tongue base } \\
\text { retraction exercises, super } \\
\text { supraglottic swallow, and } \\
\text { the Mendelssohn maneuver } \\
\text { Group 2: control group } \\
\text { only receive symptomatic } \\
\text { dysphagia treatment }\end{array}$ & $\begin{array}{l}\text { Prophylactic swallowing therapy } \\
\text { improves swallowing at } 3 \text { and } 6 \\
\text { months; later there were no } \\
\text { group differences found }\end{array}$ \\
\hline $\begin{array}{l}\text { Kraaijenga et al. } \\
2014[35]\end{array}$ & $\begin{array}{l}\text { Swallowing and } \\
\text { voice }\end{array}$ & $\begin{array}{c}\text { Daily practice from the start of } \\
\text { the treatment until } 1 \text { year after } \\
\text { treatment }\end{array}$ & $\begin{array}{l}\text { Two combined groups: } \\
\text { TheraBite System and } \\
\text { standard logopedic } \\
\text { swallowing exercises (the } \\
\text { same cohort as van der } \\
\text { Molen et al. 2011 [73]) }\end{array}$ & $\begin{array}{l}\text { Minimal voice and swallowing } \\
\text { difficulties were found } 60 \text { months } \\
\text { after treatment in patients treated } \\
\text { with prophylactic swallowing } \\
\text { exercises }\end{array}$ \\
\hline $\begin{array}{l}\text { Sanguineti et al. } \\
2014[40]\end{array}$ & Voice & $\begin{array}{l}75.8 \% \text { of the patients received } \\
\text { speech therapy. No therapy was } \\
\text { provided to } 30 \text { patients } \\
\text { No specific data provided on } \\
\text { treatment frequency/intensity }\end{array}$ & $\begin{array}{l}\text { No description of exercises } \\
\text { provided }\end{array}$ & $\begin{array}{l}\text { No specific conclusions of } \\
\text { influence of provided therapy on } \\
\text { primary outcomes described }\end{array}$ \\
\hline $\begin{array}{l}\text { Starmer et al. } \\
2014 \text { [69] }\end{array}$ & Swallowing & $\begin{array}{c}\text { Patients received prophylactic } \\
\text { swallowing and trismus exercises }\end{array}$ & $\begin{array}{l}\text { No description of exercises } \\
\text { provided }\end{array}$ & $\begin{array}{l}\text { No specific conclusions of } \\
\text { influence of provided therapy on } \\
\text { primary outcomes described }\end{array}$ \\
\hline $\begin{array}{l}\text { van der Molen et al. } \\
2011[73]\end{array}$ & Swallowing & $\begin{array}{c}\text { Patients received instructions in } \\
\text { advance of their oncological } \\
\text { treatment. Three times daily } \\
\text { exercises }\end{array}$ & $\begin{array}{l}\text { Group 1: range-of-motion } \\
\text { exercises and three } \\
\text { strengthening exercises, } \\
\text { that is, the effortful swallow, } \\
\text { the Masako maneuver, and } \\
\text { the super supraglottic } \\
\text { swallow. Stretch holding for } \\
\text { 10-30 seconds at a point of } \\
\text { mild discomfort } \\
\text { Group 2: stretch of the } \\
\text { mouth using the TheraBite } \\
\text { System and a strengthening } \\
\text { exercise: swallowing with } \\
\text { the tongue elevated to the } \\
\text { palate while maintaining } \\
\text { mouth opening at } 50 \% \text { of } \\
\text { its maximum. Stretch } \\
\text { holding for } 10-30 \text { seconds } \\
\text { at a point of mild } \\
\text { discomfort }\end{array}$ & $\begin{array}{l}\text { Similar outcomes in both groups } \\
\text { were found. Preventive } \\
\text { rehabilitation can improve early } \\
\text { posttreatment functional } \\
\text { outcomes }\end{array}$ \\
\hline $\begin{array}{l}\text { van der Molen et al. } \\
2012[44]\end{array}$ & Voice & $\begin{array}{l}\text { No specific speech or voice } \\
\text { therapy }\end{array}$ & N/A & N/A \\
\hline $\begin{array}{l}\text { van der Molen et al. } \\
2013[74]\end{array}$ & $\begin{array}{l}\text { Swallowing and } \\
\text { trismus }\end{array}$ & $\begin{array}{l}\text { Study was aimed at describing } \\
\text { dose-effect relationships in two } \\
\text { treatment groups described in } \\
\text { earlier study. References to other } \\
\text { published study where treatment } \\
\text { regime is described }\end{array}$ & $\begin{array}{l}\text { Group 1: standard exercises } \\
\text { Group 2: experimental } \\
\text { exercises }\end{array}$ & $\begin{array}{l}\text { Any possible difference between } \\
\text { the two included treatment } \\
\text { groups is not described, nor } \\
\text { possible influence of the } \\
\text { respective treatments }\end{array}$ \\
\hline
\end{tabular}

HNC: head and neck cancer; HRQoL: health-related quality of life; MIO: maximum incisal opening; ROM: range of motion. 
voice and swallowing commonly do not recover to the level prior to the oncological intervention [16]. Regarding effectiveness of voice treatments, the following multidimensional assessment is recommended [82]: a videolaryngostroboscopy recording of the laryngeal structures and the vocal fold vibration; an acoustic and a perceptual analysis of voice; a voice-related questionnaire on QoL (e.g., the Voice Handicap Index) [83]; and a functional health status questionnaire. Such a protocol would be in line with the recommendations for functional assessment of voice pathology as described by the Committee on Phoniatrics of the European Laryngological Society [84].

When describing aspects of swallowing function, both fiber optic endoscopic evaluation of swallowing and videofluoroscopy are considered to be the gold standard in dysphagia assessment [85]. In addition to these tools, questionnaires on HRQoL and functional health status are recommended and should be integrated in the overall swallowing assessment protocol. Repeated measurements of outcome measures should be performed in order to monitor any side effects of the oncological intervention, to detect spontaneous recovery, and to measure the effects of the speech pathology interventions. Apart from baseline measurements, posttreatment and follow-up measurements should be used to monitor functional and QoL outcomes.

Additional research is needed to develop clinical practice guidelines to support evidence-based practice in the area of dysphagia, speech, voice, and trismus following radiotherapy and/or chemotherapy in patients with head and neck carcinoma. These practice guidelines should bring together the best available current evidence within a specific clinical area, formulating evidence-based recommendations for clinicians and present choices between different interventions that have an impact on health and use of resources [86]. This systematic review summarised the effects of radiotherapy and/or chemotherapy on the function of the upper aerodigestive tract in patients with head and neck cancer. However, because of the marked variation in treatment protocols and patient characteristics, outcome data from the included studies cannot be easily generalised. Recommendations for future studies advocate the use of a multidimensional assessment protocol, using well-validated measures and standardised pretreatment, posttreatment, and follow-up measurements, thus allowing for future meta-analysis of homogeneous outcomes.

\section{Conclusion}

The studies included in this systematic review described a wide variety of outcomes in patients with HNC following radiotherapy and/or chemotherapy. The findings about the long-term functional implications of radiotherapy and/or chemotherapy in patients with HNC are inconclusive as a result of the wide range of outcome measures used and the possible influence of underreported speech therapy.

Future researchers need to consider targeting more homogeneous groups using standardised treatment protocols to improve the treatment outcomes, thereby decreasing the side effects of the oncological treatments. Findings of these studies need to inform the decision-making process in the treatment of HNC so complications can be better predicted with due consideration of the possible negative side effects to the upper aerodigestive tract. Although the main objective of most studies was to determine curing rates, the importance of the functional implications of the side effects of oncology treatments should not be overlooked, particularly their impact on QoL. Finally, more research is needed to gain a full understanding of the complexity and variety in the effects of radiotherapy and/or chemotherapy on the functions of the upper aerodigestive tract following HNC.

\section{Competing Interests}

All authors declare no competing interests or financial disclosures.

\section{References}

[1] A. M. Kreeft, L. Van Der Molen, F. J. Hilgers, and A. J. Balm, "Speech and swallowing after surgical treatment of advanced oral and oropharyngeal carcinoma: a systematic review of the literature," European Archives of Oto-Rhino-Laryngology, vol. 266, no. 11, pp. 1687-1698, 2009.

[2] S. N. Rogers, S. A. Ahad, and A. P. Murphy, "A structured review and theme analysis of papers published on 'quality of life' in head and neck cancer: 2000-2005," Oral Oncology, vol. 43, no. 9, pp. 843-868, 2007.

[3] R. P. Takes, P. Strojan, C. E. Silver et al., "Current trends in initial management of hypopharyngeal cancer: the declining use of open surgery," Head and Neck, vol. 34, no. 2, pp. 270-281, 2012.

[4] R. L. Nund, E. C. Ward, N. A. Scarinci, B. Cartmill, P. Kuipers, and S. V. Porceddu, "Survivors' experiences of dysphagiarelated services following head and neck cancer: implications for clinical practice," International Journal of Language \& Communication Disorders, vol. 49, no. 3, pp. 354-363, 2014.

[5] R. L. Nund, E. C. Ward, N. A. Scarinci, B. Cartmill, P. Kuipers, and S. V. Porceddu, "Carers' experiences of dysphagia in people treated for head and neck cancer: a qualitative study," Dysphagia, vol. 29, no. 4, pp. 450-458, 2014.

[6] G. P. Krisciunas, W. Sokoloff, K. Stepas, and S. E. Langmore, "Survey of usual practice: dysphagia therapy in head and neck cancer patients," Dysphagia, vol. 27, no. 4, pp. 538-549, 2012.

[7] Speech Pathology Australia. Evidence-Based Practice in Speech Pathology, 2010, http://www.speechpathologyaustralia.org.au/ library/position_statements/EBP_in_SP.pdf.

[8] American Speech-Language-Hearing Association (ASHA), Evidence-Based Practice in Communication Disorders: Position Statement, 2005.

[9] M. Miao, E. Power, and R. O'Halloran, "Factors affecting speech pathologists' implementation of stroke management guidelines: a thematic analysis," Disability and Rehabilitation, vol. 37, no. 8, pp. 674-685, 2015.

[10] J. J. Frowen and A. R. Perry, "Swallowing outcomes after radiotherapy for head and neck cancer: a systematic review," Head and Neck, vol. 28, no. 10, pp. 932-944, 2006.

[11] I. Jacobi, L. Van Der Molen, H. Huiskens, M. A. Van Rossum, and F. J. M. Hilgers, "Voice and speech outcomes of chemoradiation for advanced head and neck cancer: a systematic review," 
European Archives of Oto-Rhino-Laryngology, vol. 267, no. 10, pp. 1495-1505, 2010.

[12] L. Van Der Molen, M. A. Van Rossum, L. M. Burkhead, L. E. Smeele, and F. J. M. Hilgers, "Functional outcomes and rehabilitation strategies in patients treated with chemoradiotherapy for advanced head and neck cancer: a systematic review," European Archives of Oto-Rhino-Laryngology, vol. 266, no. 6, pp. 889-900, 2009.

[13] V. Paleri, J. W. G. Roe, P. Strojan et al., "Strategies to reduce longterm postchemoradiation dysphagia in patients with head and neck cancer: an evidence-based review," Head and Neck, vol. 36, no. 3, pp. 431-433, 2014.

[14] J. W. G. Roe, P. N. Carding, R. C. Dwivedi et al., "Swallowing outcomes following Intensity Modulated Radiation Therapy (IMRT) for head \& neck cancer-a systematic review," Oral Oncology, vol. 46, no. 10, pp. 727-733, 2010.

[15] J. Klein, J. Livergant, and J. Ringash, "Health related quality of life in head and neck cancer treated with radiation therapy with or without chemotherapy: a systematic review," Oral Oncology, vol. 50, no. 4, pp. 254-262, 2014.

[16] J. Frowen, S. Cotton, J. Corry, and A. Perry, "Impact of demographics, tumor characteristics, and treatment factors on swallowing after (chemo)radiotherapy for head and neck cancer," Head and Neck, vol. 32, no. 4, pp. 513-528, 2010.

[17] A. Liberati, D. G. Altman, J. Tetzlaff et al., "The PRISMA statement for reporting systematic reviews and meta-analyses of studies that evaluate health care interventions: explanation and elaboration," PLoS Medicine, vol. 6, no. 7, Article ID e1000100, 2009.

[18] L. M. Kmet, R. C. Lee, and L. S. Cook, Standard Quality Assessment Criteria for Evaluating Primary Research Papers from a Variety of Fields, 13, HTA Initiative, 2004.

[19] NHMRC, A Guide to the Development, Implementation and Evaluation of Clinical Practice Guidelines, 1999.

[20] D. Moher, A. Liberati, J. Tetzlaff et al., "Preferred reporting items for systematic reviews and meta-analyses: the PRISMA statement," PLoS Medicine, vol. 6, no. 7, Article ID e1000097, 2009.

[21] L.-M. Aaltonen, N. Rautiainen, J. Sellman et al., "Voice quality after treatment of early vocal cord cancer: a randomized trial comparing laser surgery with radiation therapy," International Journal of Radiation Oncology Biology Physics, vol. 90, no. 2, pp. 255-260, 2014.

[22] A. H. Ackerstaff, A. J. M. Balm, C. R. N. Rasch et al., "First-year quality of life assessment of an intraarterial (RADPLAT) versus intravenous chemoradiation phase III trial," Head and Neck, vol. 31, no. 1, pp. 77-84, 2009.

[23] J. P. Agarwal, G. K. Baccher, C. M. Waghmare et al., "Factors affecting the quality of voice in the early glottic cancer treated with radiotherapy," Radiotherapy and Oncology, vol. 90, no. 2, pp. 177-182, 2009.

[24] A. Al-Mamgani, L. Tans, P. Van Rooij, and P. C. Levendag, "A single-institutional experience of 15 years of treating T3 laryngeal cancer with primary radiotherapy, with or without chemotherapy," International Journal of Radiation Oncology Biology Physics, vol. 83, no. 3, pp. 1000-1006, 2012.

[25] A. Al-Mamgani, P. H. van Rooij, D. P. Woutersen et al., "Radiotherapy for T1-2N0 glottic cancer: a multivariate analysis of predictive factors for the long-term outcome in 1050 patients and a prospective assessment of quality of life and voice handicap index in a subset of 233 patients," Clinical Otolaryngology, vol. 38, no. 4, pp. 306-312, 2013.
[26] A. Al-Mamgani, S. L. S. Kwa, L. Tans et al., "Single vocal cord irradiation: image guided intensity modulated hypofractionated radiation therapy for Tla glottic cancer: early clinical results," International Journal of Radiation Oncology Biology Physics, vol. 93, no. 2, pp. 337-343, 2015.

[27] M. Bansal, B. K. Mohanti, N. Shah, R. Chaudhry, S. Bahadur, and N. K. Shukla, "Radiation related morbidities and their impact on quality of life in head and neck cancer patients receiving radical radiotherapy," Quality of Life Research, vol. 13, no. 2, pp. 481-488, 2004.

[28] J. R. L. Bibby, S. M. Cotton, A. Perry, and J. F. Corry, "Voice outcomes after radiotherapy treatment for early glottic cancer: assessment using multidimensional tools," Head and Neck, vol. 30, no. 5, pp. 600-610, 2008.

[29] K. Dornfeld, J. R. Simmons, L. Karnell et al., "Radiation doses to structures within and adjacent to the larynx are correlated with long-term diet- and speech-related quality of life," International Journal of Radiation Oncology Biology Physics, vol. 68, no. 3, pp. 750-757, 2007.

[30] I. Jacobi, A. Navran, L. van der Molen, W. D. Heemsbergen, F. J. M. Hilgers, and M. W. M. van den Brekel, "Radiation dose to the tongue and velopharynx predicts acoustic-articulatory changes after chemo-IMRT treatment for advanced head and neck cancer," European Archives of Oto-Rhino-Laryngology, vol. 273, no. 2, pp. 487-494, 2016.

[31] T. Karlsson, M. Johansson, P. Andréll, and C. Finizia, "Effects of voice rehabilitation on health-related quality of life, communication and voice in laryngeal cancer patients treated with radiotherapy: a randomised controlled trial," Acta Oncologica, vol. 54, no. 7, pp. 1017-1024, 2015.

[32] T. Karlsson, L. Bergström, E. Ward, and C. Finizia, "A prospective longitudinal study of voice characteristics and healthrelated quality of life outcomes following laryngeal cancer treatment with radiotherapy," Acta Oncologica, vol. 55, no. 6, pp. 693-699, 2016.

[33] R. Kazi, R. Venkitaraman, C. Johnson et al., "Electroglottographic comparison of voice outcomes in patients with advanced laryngopharyngeal cancer treated by chemoradiotherapy or total laryngectomy," International Journal of Radiation Oncology, Biology, Physics, vol. 70, no. 2, pp. 344-352, 2008.

[34] P. Kerr, C. L. Myers, J. Butler, M. Alessa, P. Lambert, and A. L. Cooke, "Prospective functional outcomes in sequential population based cohorts of stage III/ IV oropharyngeal carcinoma patients treated with 3D conformal vs. intensity modulated radiotherapy," Journal of Otolaryngology-Head and Neck Surgery, vol. 44, article 17, 2015.

[35] S. A. C. Kraaijenga, L. van der Molen, I. Jacobi, O. HammingVrieze, F. J. M. Hilgers, and M. W. M. van den Brekel, "Prospective clinical study on long-term swallowing function and voice quality in advanced head and neck cancer patients treated with concurrent chemoradiotherapy and preventive swallowing exercises," European Archives of Oto-Rhino-Laryngology, vol. 272, no. 11, pp. 3521-3531, 2014.

[36] C. L. Lazarus, H. Husaini, K. Hu et al., "Functional outcomes and quality of life after chemoradiotherapy: baseline and 3 and 6 months post-treatment," Dysphagia, vol. 29, no. 3, pp. 365-375, 2014.

[37] B. B. Mittal, A. Kepka, A. Mahadevan et al., "Tissue/dose compensation to reduce toxicity from combined radiation and chemotherapy for advanced head and neck cancers," International Journal of Cancer, vol. 96, pp. 61-70, 2001. 
[38] G. Niedzielska, A. Niedzielski, and D. Toman, "Voice after radiotherapy of the larynx carcinoma," Radiotherapy and Oncology, vol. 97, no. 2, pp. 276-280, 2010.

[39] A. J. Remmelts, F. J. P. Hoebers, W. M. C. Klop, A. J. M. Balm, O. Hamming-Vrieze, and M. W. M. Van Den Brekel, "Evaluation of lasersurgery and radiotherapy as treatment modalities in early stage laryngeal carcinoma: tumour outcome and quality of voice," European Archives of Oto-Rhino-Laryngology, vol. 270, no. 7, pp. 2079-2087, 2013.

[40] G. Sanguineti, F. Ricchetti, T. McNutt, B. Wu, and C. Fiorino, "Dosimetric predictors of dysphonia after intensity-modulated radiotherapy for oropharyngeal carcinoma," Clinical Oncology, vol. 26, no. 1, pp. 32-38, 2014.

[41] J. G. Spector, D. G. Sessions, K. S. Chao et al., "Stage I (t1 N0 M0) squamous cell carcinoma of the laryngeal glottis: therapeutic results and voice preservation," Head \& Neck, vol. 21, no. 8, pp. 707-717, 1999.

[42] L. Tuomi, T. Karlsson, M. Johansson, and C. Finizia, "Healthrelated quality of life and voice following radiotherapy for laryngeal cancer-a comparison between glottic and supraglottic tumours," Acta Oncologica, vol. 54, no. 1, pp. 73-79, 2015.

[43] I. M. Verdonck-de Leeuw, R. B. Keus, F. J. M. Hilgers et al., "Consequences of voice impairment in daily life for patients following radiotherapy for early glottic cancer: voice quality, vocal function, and vocal performance," International Journal of Radiation Oncology, Biology, Physics, vol. 44, no. 5, pp. 10711078, 1999.

[44] L. van der Molen, M. A. Van Rossum, I. Jacobi et al., "Preand posttreatment voice and speech outcomes in patients with advanced head and neck cancer treated with chemoradiotherapy: expert listeners' and patient's perception," Journal of Voice, vol. 26, no. 5, pp. 664.e25-664.e33, 2012.

[45] J. Agarwal, V. Palwe, D. Dutta et al., "Objective assessment of swallowing function after definitive concurrent (Chemo)radiotherapy in patients with head and neck cancer," Dysphagia, vol. 26, no. 4, pp. 399-406, 2011.

[46] L. M. Akst, J. Chan, P. Elson, J. Saxton, M. Strome, and D. Adelstein, "Functional outcomes following chemoradiotherapy for head and neck cancer," Otolaryngology-Head and Neck Surgery, vol. 131, no. 6, pp. 950-957, 2004.

[47] A. Al-Mamgani, R. Mehilal, P. H. Van Rooij, L. Tans, A. Sewnaik, and P. C. Levendag, "Toxicity, quality of life, and functional outcomes of 176 hypopharyngeal cancer patients treated by (Chemo)radiation: the impact of treatment modality and radiation technique," The Laryngoscope, vol. 122, no. 8, pp. 1789-1795, 2012.

[48] D. Buchbinder, R. B. Currivan, A. J. Kaplan, and M. L. Urken, "Mobilization regimens for the prevention of jaw hypomobility in the radiated patient: a comparison of three techniques," Journal of Oral and Maxillofacial Surgery, vol. 51, no. 8, pp. 863867, 1993.

[49] J. J. Caudell, P. E. Schaner, R. A. Desmond, R. F. Meredith, S. A. Spencer, and J. A. Bonner, "Dosimetric factors associated with long-term dysphagia after definitive radiotherapy for squamous cell carcinoma of the head and neck," International Journal of Radiation Oncology, Biology, Physics, vol. 76, no. 2, pp. 403-409, 2010.

[50] M. E. M. C. Christianen, I. M. Verdonck-De Leeuw, P. Doornaert et al., "Patterns of long-term swallowing dysfunction after definitive radiotherapy or chemoradiation," Radiotherapy and Oncology, vol. 117, no. 1, pp. 139-144, 2015.
[51] E. E. W. Cohen, D. J. Haraf, M. A. List et al., "High survival and organ function rates after primary chemoradiotherapy for intermediate-stage squamous cell carcinoma of the head and neck treated in a multicenter phase II trial," Journal of Clinical Oncology, vol. 24, no. 21, pp. 3438-3444, 2006.

[52] P. U. Dijkstra, M. W. Sterken, R. Pater, F. K. L. Spijkervet, and J. L. N. Roodenburg, "Exercise therapy for trismus in head and neck cancer," Oral Oncology, vol. 43, no. 4, pp. 389-394, 2007.

[53] F. Y. Feng, H. M. Kim, T. H. Lyden et al., "Intensity-modulated radiotherapy of head and neck cancer aiming to reduce dysphagia: early dose-effect relationships for the swallowing structures," International Journal of Radiation Oncology Biology Physics, vol. 68, no. 5, pp. 1289-1298, 2007.

[54] F. Y. Feng, H. M. Kim, T. H. Lyden et al., "Intensity-modulated chemoradiotherapy aiming to reduce dysphagia in patients with oropharyngeal cancer: clinical and functional results," Journal of Clinical Oncology, vol. 28, no. 16, pp. 2732-2738, 2010.

[55] M. Haderlein, S. Semrau, O. Ott, S. Speer, C. Bohr, and R. Fietkau, "Dose-dependent deterioration of swallowing function after induction chemotherapy and definitive chemoradiotherapy for laryngopharyngeal cancer," Strahlentherapie und Onkologie, vol. 190, no. 2, pp. 192-198, 2014.

[56] K. A. Hutcheson, J. S. Lewin, F. C. Holsinger et al., "Long-term functional and survival outcomes after induction chemotherapy and risk-based definitive therapy for locally advanced squamous cell carcinoma of the head and neck," Head and Neck, vol. 36, no. 4, pp. 474-480, 2014.

[57] T. Kotz, A. D. Federman, J. Kao et al., "Prophylactic swallowing exercises in patients with head and neck cancer undergoing chemoradiation: a randomized trial," Archives of Otolaryngology-Head and Neck Surgery, vol. 138, no. 4, pp. 376-382, 2012.

[58] R. Kumar, S. Madanikia, H. Starmer et al., "Radiation dose to the floor of mouth muscles predicts swallowing complications following chemoradiation in oropharyngeal squamous cell carcinoma," Oral Oncology, vol. 50, no. 1, pp. 65-70, 2014.

[59] M. A. List, A. Siston, D. Haraf et al., "Quality of life and performance in advanced head and neck cancer patients on concomitant chemoradiotherapy: a prospective examination," Journal of Clinical Oncology, vol. 17, no. 3, pp. 1020-1028, 1999.

[60] B. T. McLaughlin, A. S. Gokhale, Y. Shuai et al., "Management of patients treated with chemoradiotherapy for head and neck cancer without prophylactic feeding tubes: the University of Pittsburgh experience," The Laryngoscope, vol. 120, no. 1, pp. 7175, 2010.

[61] T. Murry, R. Madasu, A. Martin, and K. T. Robbins, "Acute and chronic changes in swallowing and quality of life following intraarterial chemoradiation for organ preservation in patients with advanced head and neck cancer," Head and Neck, vol. 20, no. 1, pp. 31-37, 1998.

[62] A. Nourissat, I. Bairati, E. Samson et al., "Predictors of weight loss during radiotherapy in patients with stage I or II head and neck cancer," Cancer, vol. 116, no. 9, pp. 2275-2283, 2010.

[63] S. Ottosson, U. Lindblom, P. Wahlberg et al., "Weight loss and body mass index in relation to aspiration in patients treated for head and neck cancer: a long-term follow-up," Supportive Care in Cancer, vol. 22, no. 9, pp. 2361-2369, 2014.

[64] N. Pauli, J. Johnson, C. Finizia, and P. Andréll, “The incidence of trismus and long-term impact on health-related quality of life in patients with head and neck cancer," Acta Oncologica, vol. 52, no. 6, pp. 1137-1145, 2013. 
[65] B. R. Pauloski, A. W. Rademaker, J. A. Logemann et al., "Relationship between swallow motility disorders on videofluorography and oral intake in patients treated for head and neck cancer with radiotherapy with or without chemotherapy," Head and Neck, vol. 28, no. 12, pp. 1069-1076, 2006.

[66] A. W. Rademaker, E. F. Vonesh, J. A. Logemann et al., "Eating ability in head and neck cancer patients after treatment with chemoradiation: a 12-month follow-up study accounting for dropout," Head and Neck, vol. 25, no. 12, pp. 1034-1041, 2003.

[67] J. K. Salama, K. M. Stenson, M. A. List et al., "Characteristics associated with swallowing changes after concurrent chemotherapy and radiotherapy in patients with head and neck cancer," Archives of Otolaryngology-Head and Neck Surgery, vol. 134, no. 10, pp. 1060-1065, 2008.

[68] R. Scrimger, A. Kanji, M. Parliament et al., "Correlation between saliva production and quality of life measurements in head and neck cancer patients treated with intensity-modulated radiotherapy," American Journal of Clinical Oncology, vol. 30, no. 3, pp. 271-277, 2007.

[69] H. M. Starmer, D. Tippett, K. Webster et al., "Swallowing outcomes in patients with oropharyngeal cancer undergoing organ-preservation treatment," Head and Neck, vol. 36, no. 10, pp. 1392-1397, 2014.

[70] K. M. Stenson, R. Kunnavakkam, E. E. W. Cohen et al., "Chemoradiation for patients with advanced oral cavity cancer," The Laryngoscope, vol. 120, no. 1, pp. 93-99, 2010.

[71] L. Strigari, M. Benassi, G. Arcangeli, V. Bruzzaniti, G. Giovinazzo, and L. Marucci, "A novel dose constraint to reduce xerostomia in head-and-neck cancer patients treated with intensity-modulated radiotherapy," International Journal of Radiation Oncology Biology Physics, vol. 77, no. 1, pp. 269-276, 2010.

[72] J. M. Vainshtein, D. H. Moon, F. Y. Feng, D. B. Chepeha, A. Eisbruch, and M. H. Stenmark, "Long-term quality of life after swallowing and salivary-sparing chemo-intensity modulated radiation therapy in survivors of human papillomavirusrelated oropharyngeal cancer," International Journal of Radiation Oncology Biology Physics, vol. 91, no. 5, pp. 925-933, 2015.

[73] L. van der Molen, M. A. van Rossum, L. M. Burkhead, L. E. Smeele, C. R. N. Rasch, and F. J. M. Hilgers, "A randomized preventive rehabilitation trial in advanced head and neck cancer patients treated with chemoradiotherapy: feasibility, compliance, and short-term effects," Dysphagia, vol. 26, no. 2, pp. 155-170, 2011.

[74] L. van der Molen, W. D. Heemsbergen, R. De Jong et al., "Dysphagia and trismus after concomitant chemo-IntensityModulated Radiation Therapy (chemo-IMRT) in advanced head and neck cancer; dose-effect relationships for swallowing and mastication structures," Radiotherapy and Oncology, vol. 106, no. 3, pp. 364-369, 2013.

[75] G. Vlacich, D. E. Spratt, R. Diaz et al., "Dose to the inferior pharyngeal constrictor predicts prolonged gastrostomy tube dependence with concurrent intensity-modulated radiation therapy and chemotherapy for locally-advanced head and neck cancer," Radiotherapy and Oncology, vol. 110, no. 3, pp. 435-440, 2014.

[76] J. A. Wilson, P. N. Carding, and J. M. Patterson, "Dysphagia after nonsurgical head and neck cancer treatment: patients' perspectives," Otolaryngology—Head and Neck Surgery, vol. 145, no. 5, pp. 767-771, 2011.

[77] J. I. A. Urdaniz, F. A. De La Vega, A. M. Burgaleta et al., "Quality of life in patients with locally advanced head and neck cancer treated with chemoradiotherapy. Comparison of two protocols using the EORTC questionnaires (QLQ-C30, H and N35)," Clinical and Translational Oncology, vol. 7, no. 9, pp. 398-403, 2005.

[78] A. Bottomley, G. Tridello, C. Coens et al., "An international phase 3 trial in head and neck cancer: quality of life and symptom results: EORTC 24954 on behalf of the EORTC head and neck and the EORTC radiation oncology group," Cancer, vol. 120, no. 3, pp. 390-398, 2014.

[79] I. M. Verdonck-De Leeuw, L. M. Buffart, M. W. Heymans et al., "The course of health-related quality of life in head and neck cancer patients treated with chemoradiation: A Prospective Cohort Study," Radiotherapy and Oncology, vol. 110, no. 3, pp. 422-428, 2014.

[80] J. A. Langendijk, P. Doornaert, I. M. Verdonck-de Leeuw, C. R. Leemans, N. K. Aaronson, and B. J. Slotman, "Impact of late treatment-related toxicity on quality of life among patients with head and neck cancer treated with radiotherapy," Journal of Clinical Oncology, vol. 26, no. 22, pp. 3770-3776, 2008.

[81] K. Jensen, A. Bonde Jensen, and C. Grau, "The relationship between observer-based toxicity scoring and patient assessed symptom severity after treatment for head and neck cancer. A correlative cross sectional study of the DAHANCA toxicity scoring system and the EORTC quality of life questionnaires," Radiotherapy and Oncology, vol. 78, no. 3, pp. 298-305, 2006.

[82] R. Speyer, "Effects of voice therapy: a systematic review," Journal of Voice, vol. 22, no. 5, pp. 565-580, 2008.

[83] B. H. Jacobson, A. Johnson, C. Grywalski et al., "The Voice Handicap Index (VHI)," American Journal of Speech-Language Pathology, vol. 6, no. 3, pp. 66-69, 1997.

[84] P. H. Dejonckere, P. Bradley, P. Clemente et al., "A basic protocol for functional assessment of voice pathology, especially for investigating the efficacy of (phonosurgical) treatments and evaluating new assessment techniques," European Archives of Oto-Rhino-Laryngology, vol. 258, no. 2, pp. 77-82, 2001.

[85] R. Speyer, L. Baijens, M. Heijnen, and I. Zwijnenberg, "Effects of therapy in oropharyngeal dysphagia by speech and language therapists: a systematic review," Dysphagia, vol. 25, no. 1, pp. 40 65, 2010.

[86] World Health Organization, WHO Handbook for Guideline Development, 2012, http://apps.who.int/iris/bitstream/10665/ 75146/1/9789241548441_eng.pdf. 


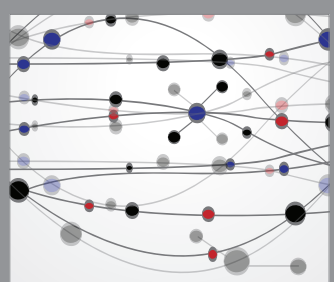

The Scientific World Journal
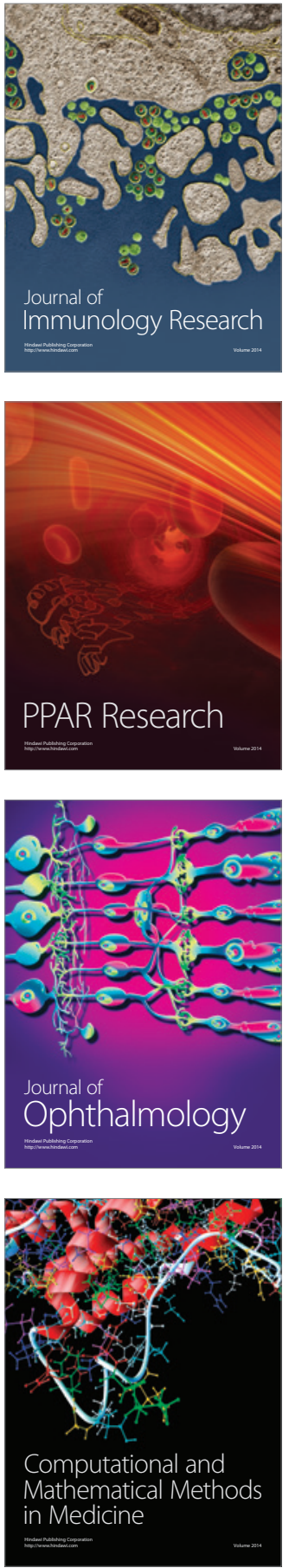

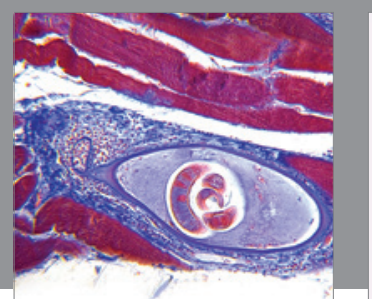

Gastroenterology Research and Practice

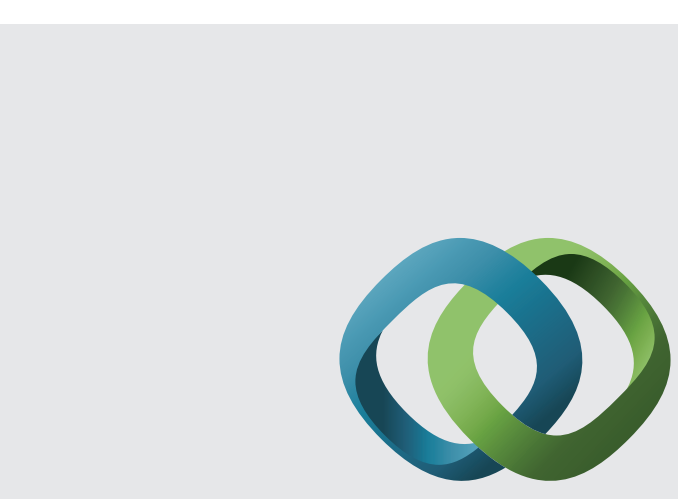

\section{Hindawi}

Submit your manuscripts at

http://www.hindawi.com
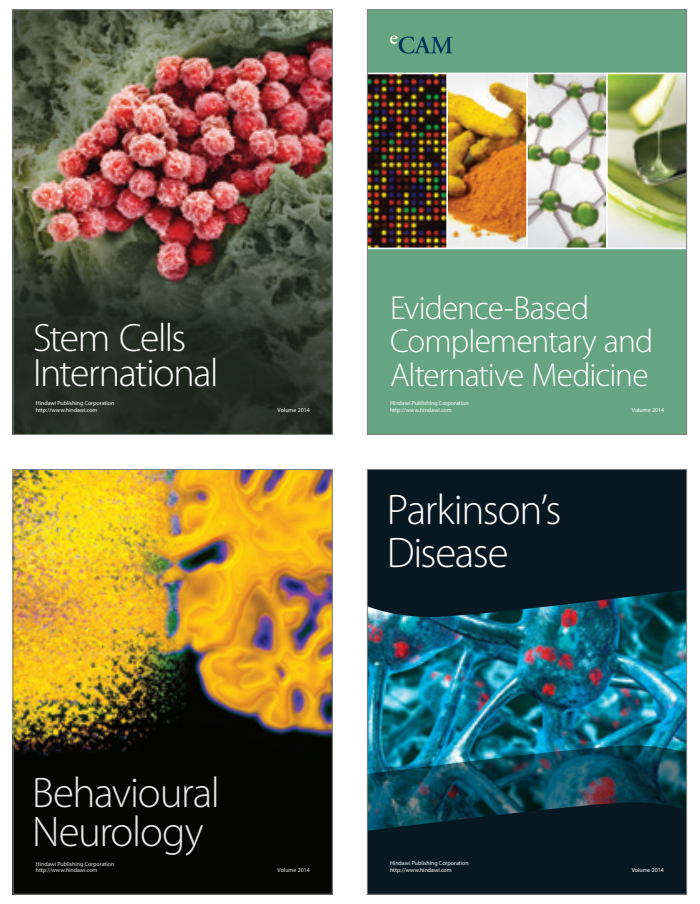
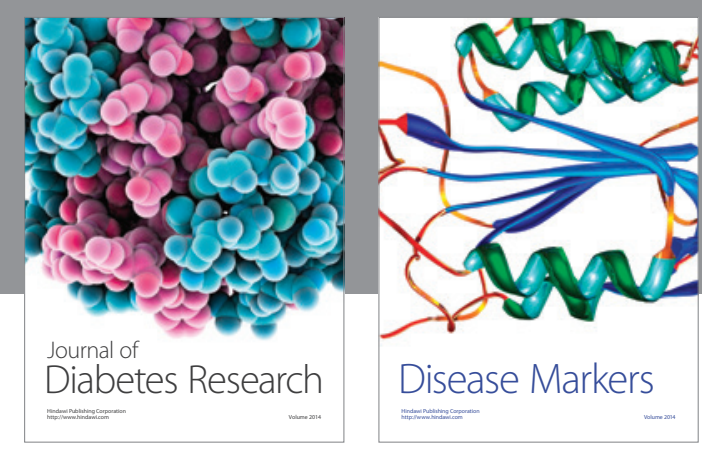

Disease Markers
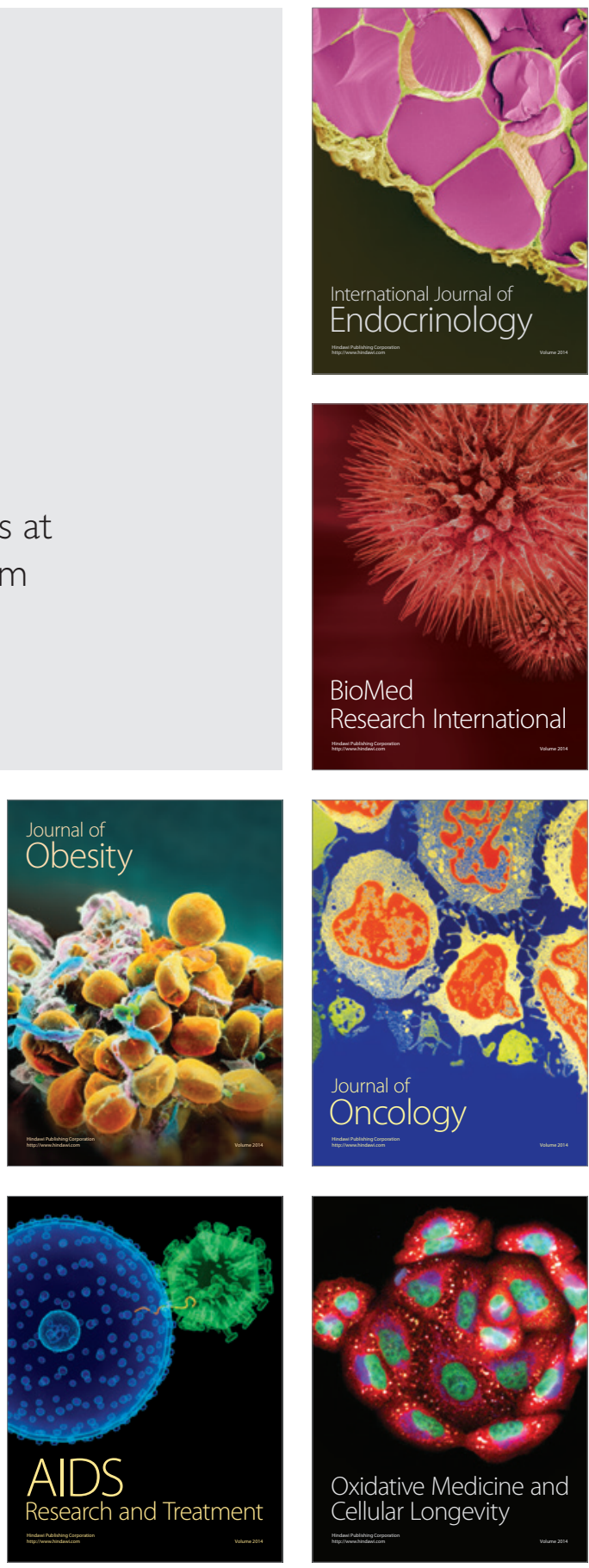